\title{
Synthesis and Properties of Porphyrin Nanotubes
}

\author{
Renée Haver and Harry L. Anderson* \\ Department of Chemistry, University of Oxford, Chemistry Research Laboratory, Oxford OX1 3TA, harry.anderson@chem.ox.ac.uk
}

Dedicated to François Diederich on the occasion of his retirement

\begin{abstract}
Discrete $\pi$-conjugated zinc porphyrin nanotubes are investigated as molecular analogues of carbon nanotubes. These porphyrin nanotubes have a diameter of $2.4 \mathrm{~nm}$ ( $\mathrm{Zn}-\mathrm{Zn}$ distance) and lengths of up to $3.6 \mathrm{~nm}$, measured to the van der Waals surfaces of the outer $\beta$-pyrrole hydrogen atoms, or 4.5 $\mathrm{nm}$ measured to the para hydrogen atoms of the aryl groups. We explore three different strategies for synthesizing these nanotubes. The first two strategies use a template to achieve direct or sequential stave-joining, respectively, and proceed via linear oligomers that pre-define the length of the nanotube. These strategies are applied to synthesize porphyrin nanotubes containing 12- or 18-porphyrin subunits, with ethynylene (C2) or butadiynylene (C4) links between the 6-porphyrin nanorings. The third strategy involves the covalent stacking of pre-formed 6-porphyrin nanorings to form a 12 porphyrin nanotube, without using a template to guide this coupling reaction. The nanotubes show strongly red-shifted absorption spectra and low fluorescence quantum yields, indicating structural rigidity and extensive $\pi$-conjugation.
\end{abstract}

Keywords: Porphyrin $\bullet$ Nanotube $\bullet$ Supramolecular Chemistry $\bullet \pi$-Conjugation $\bullet$ Template-Directed Synthesis

\section{Introduction}

Multi- and single- walled carbon nanotubes (CNTs) ${ }^{[1-3]}$ are intensively investigated because their remarkable charge transport and mechanical behavior make them promising for applications in nano-electronics and mechanically reinforced materials. ${ }^{[4-7]}$ The properties of CNTs depend on their specific diameter and chirality, and current synthetic methods result in mixtures of species and hence a range of properties. The inaccessibility of uniform-diameter, single-chirality CNTs is a significant impediment to the development of CNT-based functional materials. ${ }^{[8-10]}$ Synthetic efforts towards atomically precise CNTs include a bottom-up "total synthesis" approach, and short CNT structural fragments, ${ }^{[11-18]}$ such as $[n]$ cycloparaphenylenes, ${ }^{[19-21]}$ can act as templates to direct the growth of structurally uniform CNTs. ${ }^{[22-25]}$

The synthesis of organic molecular and supramolecular nanotubes has been widely investigated. ${ }^{[26-30]}$ The structural versatility of organic nanotubes (ONTs) make them promising nano-porous materials. ONTs have attracted interest as conduits of chemical information and for their potential in encapsulation and storage. Recent advances in the synthesis of ONTs include the preparation of covalently linked nanotubes via heat- or light-induced polymerization of columnar stacked butadiyne-linked macrocycles, ${ }^{[31-33]}$ and non-covalent tubular assemblies through hydrogenbond directed stacking of cyclic peptide $\mathrm{e}^{[34-36]}$ and non-peptide ${ }^{[37-41]}$ precursors. However, these nanotubes lack precise synthetic control and do not exhibit (extensive) $\pi$-conjugation, making then unsuitable as substitutes for CNTs. ${ }^{[42-45]}$ Tubular porphyrin nanostructures include multilayer amorphous coatings of cobalt porphyrins on CNTs that show catalytic activity in water oxidation/proton reduction, ${ }^{[46,47]}$ and supramolecular nanotubes of meso-tetra(4-sulfonatophenyl)porphine that display interesting exciton mobility. ${ }^{[48-52]}$ These non-covalent tubes lack structural robustness, monodispersity or full $\pi$-conjugation.
The most commonly used metal-ligand interaction in porphyrin chemistry is the axial binding of zinc porphyrins to nitrogen ligands. This metal-ligand interaction has been widely exploited in the templatedirected synthesis of various porphyrin nanostructures by the groups of Sanders, ${ }^{[53,54]}$ Lindsey, ${ }^{[55-57]}$ Gossauer ${ }^{[58,59]}$ and Anderson. ${ }^{[60,61]}$ The porphyrin subunits in most of the nanostructures studied in Oxford are linked by butadiyne (C4) bridges, leading to strong electronic communication between the porphyrin centers. ${ }^{[62,63]}$ Various fully $\pi$-conjugated porphyrin nanorings have been prepared and studied for their electronic and optical properties. ${ }^{[61,64-66]}$ Beyond the two-dimensionality of the porphyrin nanorings, we prepared a spiro-fused array of 11 porphyrin units, ${ }^{[67]}$ and a porphyrin nanoball consisting of two intersecting nanorings containing six and 10 porphyrin units. ${ }^{[68]}$ In both nanostructures, fluorescence upconversion spectroscopy experiments demonstrated rapid exciton delocalization (within 0.3 ps), indicating extensive electronic communication around the entire $\pi$-system.

Recently, we reported the template-directed synthesis of a discrete molecular nanotube with three-dimensional $\pi$-conjugation, constructed from 12 porphyrin units arranged in two conjoined 6-porphyrin nanorings; $\boldsymbol{t}$-P12·(T6) ${ }_{2}{ }^{[60]}$ This 12-porphyrin nanotube was prepared via direct stavejoining (Figure 1a) from a porphyrin dimer (I-P2b, Scheme 1); the structures of $\boldsymbol{t}$-P12 and the hexapyridyl template T6 are shown in Figures 2 and 3, respectively. This discrete molecular nanotube has a length of 3.2 $\mathrm{nm}$ measured to the para hydrogen atoms of the aryl groups, which, to the best of our knowledge, is longer than all previously synthesized $\pi$ conjugated molecular belts, barrels or nanotubes. ${ }^{[13,14,21,27]}$ Ultrafast timeresolved fluorescence spectroscopy showed strong coupling between the components of the nanotube, manifested by rapid energy migration from excited states associated with the staves of the barrel (z-direction) to the 6-porphyrin nanoring component ( $x y$-plane). These results prompted us to explore the synthesis and properties of other porphyrin nanotubes. 


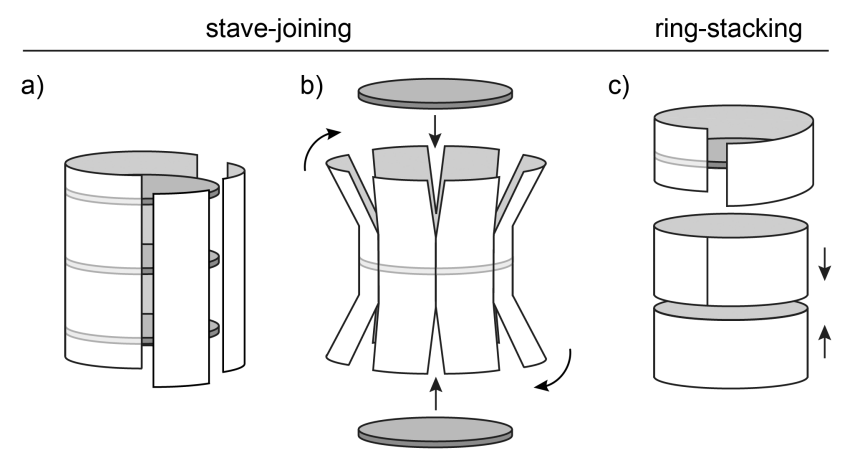

Figure 1. Schematic representation of three strategies to synthesize porphyrin nanotubes. a) Direct stave-joining. b) Sequential stave-joining. c) Ring stacking.

Here we report the design and synthesis of porphyrin nanotubes constructed from 12 and 18 porphyrin subunits with either acetylene (C2; denoted as * in the compound label) or butadiyne (C4) links between the conjoined 6-porphyrin nanorings; $t$-P12*, $t$-P12, $t$-P18 and $t$-P18* (Figure 2; $\boldsymbol{t}$-PN denotes a porphyrin nanotube constructed from $N$ porphyrin subunits). The C2-linked porphyrin nanotubes show enhanced conjugation over the extended $\pi$-system. ${ }^{[69-71]}$ We explore an unprecedented ringstacking strategy to a 12-porphyrin nanotube that in theory could be extended to build infinite-length porphyrin nanotubes. Furthermore, we discuss different template-directed strategies to prepare an 18-porphyrin nanotube, the longest $\pi$-conjugated molecular nanotube to date.

We explore three synthetic strategies for the synthesis of porphyrin nanotubes longer than $\boldsymbol{t}$-P12·(T6) $)_{2}$. The first and second strategies comprise stave-joining from linear porphyrin oligomers that predefine the length of the nanotube in either a direct (Figure 1a) or sequential (Figure 1b) fashion, respectively. From a synthetic point of view, the direct stavejoining approach, in which a linear oligomer predefines the length of the nanotube, becomes increasingly challenging when targeting longer nanotubes, as each increment in tube-length requires the synthesis of the designated porphyrin oligomer. More importantly, coupling of butadiynelinked oligomers longer than dimer can lead to mismatched coupling and polymerization. Sequential stave-joining prevents mismatched coupling by first connecting the staves at their centers, enabling the synthesis of longer porphyrin nanotubes from linear precursors. The third strategy comprises the covalent "stacking" of pre-formed porphyrin nanorings (Figure 1c). In principle, this strategy could be extended to access extremely long nanotubes.

\section{Results and Discussion}

Stave-Joining and Ring-Stacking Synthesis of $\boldsymbol{t}$-P12. We previously prepared $\boldsymbol{t}$-P12·(T6 $)_{2}$ via a direct templated stave-joining synthesis from $I$ P2b. ${ }^{[60]}$ The final oligomerization was performed in the presence of T6, a radial six-legged template. The key intermediate in the synthesis of $\mathbf{I - P 2} \mathbf{b}$ is the tetra-meso-substituted zinc porphyrin monomer P1c, which was prepared from P1 using a Senge arylation to introduce the bis(trihexylsilyl)aryl solubilizing group (Scheme 1). ${ }^{[72,73]}$ Arylation was followed by metalation with zinc, bromination at the remaining free meso-position and Sonogashira cross-coupling with TMS-acetylene to give P1c. Selective removal of the TMS group to give P1d, followed by homo-coupling and subsequent removal of the four TIPS groups gave I-P2b. Cyclooligomerization of $\boldsymbol{I - P 2} \mathbf{b}$ under palladium-catalyzed oxidative conditions in the presence of $\mathbf{T} 6$ template gave $\boldsymbol{t}-\mathbf{P} \mathbf{1 2} \cdot(\mathrm{T} 6)_{2}$ in a reproducible yield of $31 \%$ (Scheme 1). The number of components (8 in total) that must successfully assemble, via the formation of twelve new C-C bonds, demonstrates the power of supramolecular self-assembly in the template-directed stavejoining synthesis of large porphyrin nanostructures from simple components.

The direct stave-joining method appears to be inherently limited to 12-porphyrin nanotubes because it would be hard to prevent coupling between the wrong sites in a longer linear precursor stave. Therefore, we have explored a ring-stacking strategy which, in theory, could afford infinite-length porphyrin nanotubes. A ring-stacking synthesis targeting porphyrin nanotubes with more than 12 porphyrin units (i.e. more than
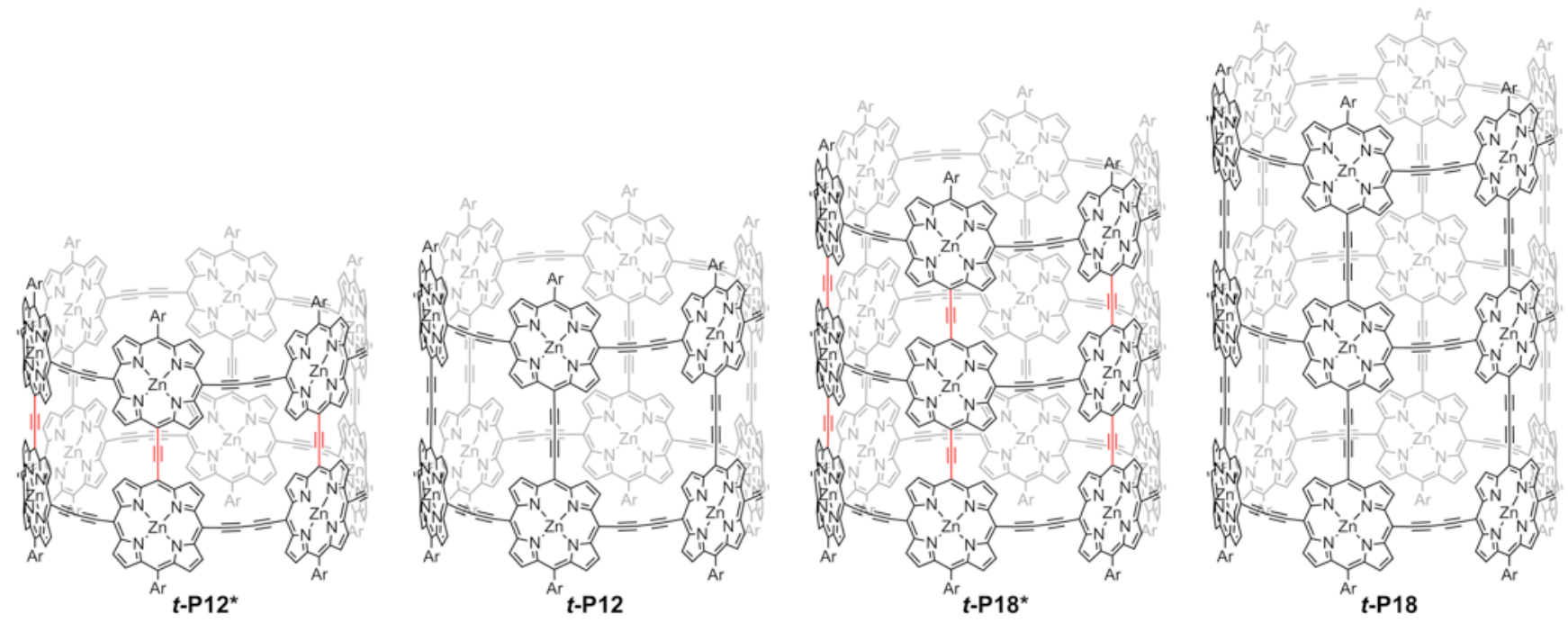

Figure 2. Molecular structure of C2- and C4-linked 12- and 18-porphyrin nanotubes. Ar = 3,5-bis(trihexylsilyl)phenyl or 3,5-bis(diisobutyloctadecylsilyl)phenyl. 

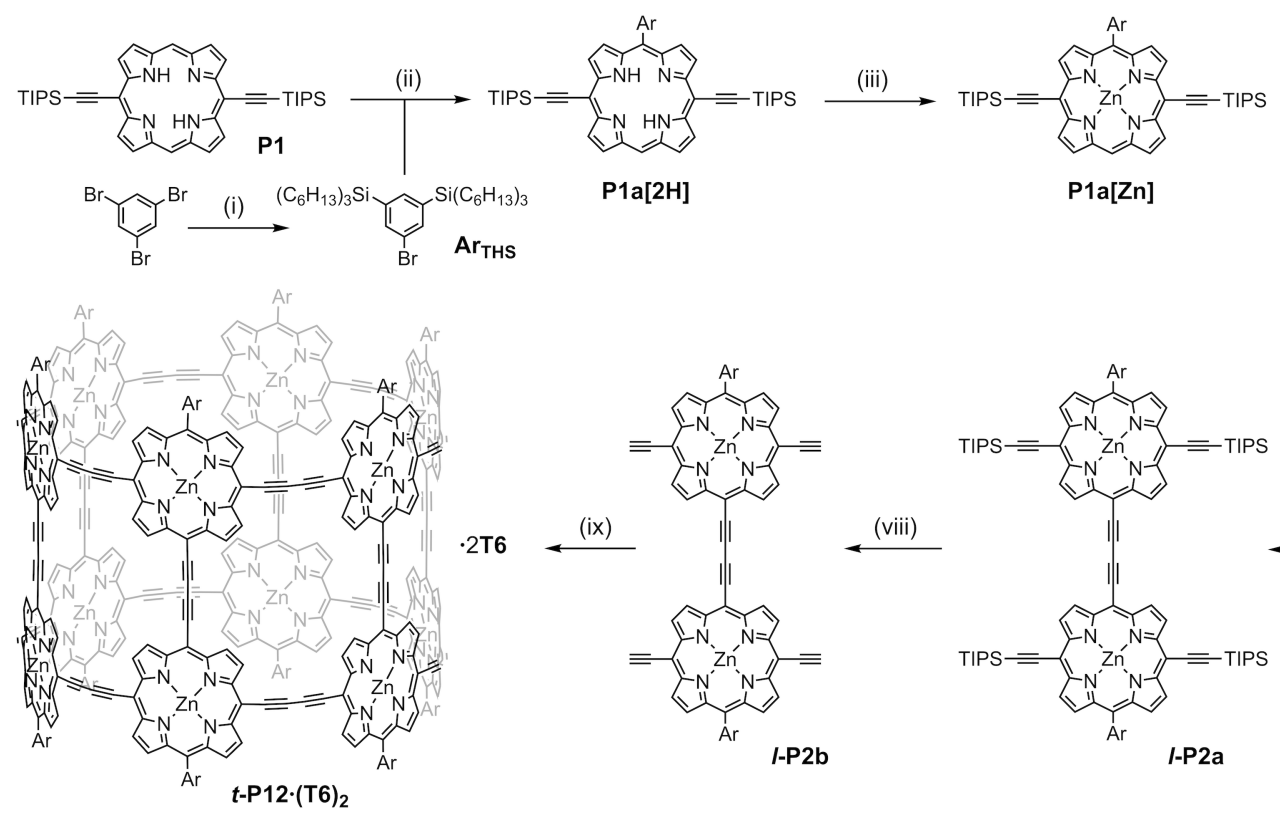

(iv)

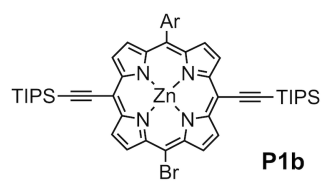

$\mathrm{P} 1 \mathrm{a}[\mathrm{Zn}]$
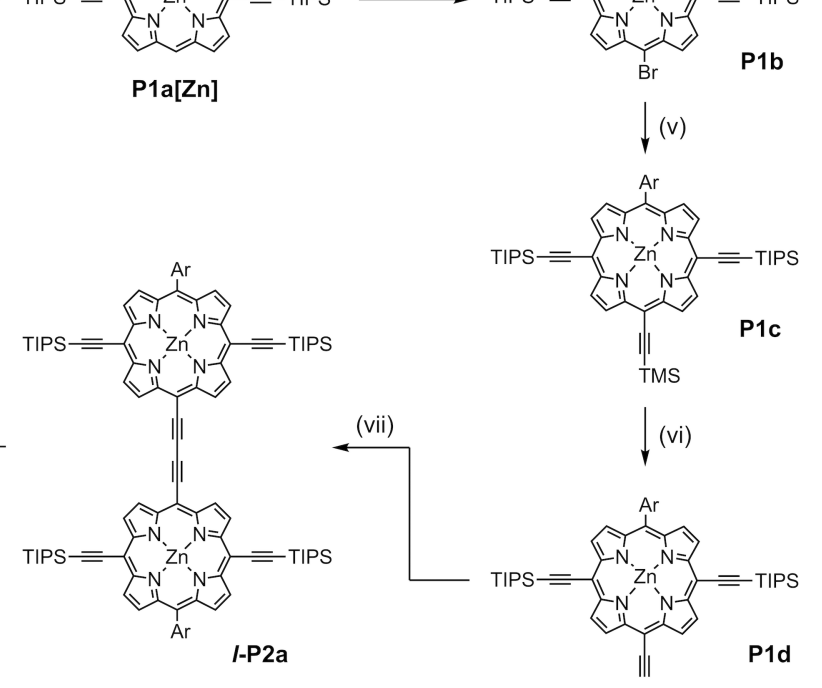

Scheme 1. Template-directed stave-joining synthesis of $t$-P12·(T6) $)_{2}$. (i) $n$-BuLi, THS-Cl, used as crude in the next step. (ii) $n-B u L i$, then $\mathrm{H}_{2} \mathrm{O}, \mathrm{DDQ}, \mathrm{Et}{ }_{3} \mathrm{~N}, 76 \%$. (iii) $\mathrm{Zn}(\mathrm{OAC})_{2} \cdot 2 \mathrm{H}_{2} \mathrm{O}$, 98\%. (iv) NBS, 67\%. (v) TMS-acetylene, $\mathrm{Pd}_{2} \mathrm{dba}_{3}, \mathrm{Cul} \mathrm{PPh}_{3}, 100 \%$. (vi) $\mathrm{K}_{2} \mathrm{CO}_{3}, 82 \%$. (vii) $\mathrm{Pd}\left(\mathrm{PPh}_{3}\right)_{2} \mathrm{Cl}_{2}, \mathrm{Cul}, 1,4$-benzoquinone, $\mathrm{N}, \mathrm{N}$-diisopropylamine, $94 \%$. (viii) TBAF, 100\%. (ix) T6, $\mathrm{Pd}\left(\mathrm{PPh}_{3}\right)_{2} \mathrm{Cl}_{2}, \mathrm{Cul}, 1,4$-benzoquinone, $\mathrm{N}, \mathrm{N}$-diisopropylamine, $31 \%{ }^{[60]}$

two rings) would require two building blocks: a capping ring which has solubilizing groups on one side of the porphyrin components and coupling moieties (e.g. free acetylenes) on the other, and a central ring which has coupling moieties on both sides (Scheme 2a). Coupling of these two rings would, in theory, give a statistical distribution of porphyrin nanotubes with a monodisperse diameter and polydisperse length.

The 12-porphyrin nanotube $(\boldsymbol{t}$-P12) is the simplest initial target to explore ring-stacking synthesis since it only requires the capping 6porphyrin nanoring as precursor (c-P6b, Scheme $2 b$ ). The key intermediate to $\mathbf{c - P 6 b}$ is tetra-meso-substituted zinc porphyrin monomer $\mathbf{P 1 g}$, which has the opposite orthogonal protecting group distribution as P1c. The preparation of $\mathbf{P} \mathbf{1 g}$ requires removal of the TIPS groups on $\mathbf{P} \mathbf{1 b}$, reprotection of the acetylenes with TMS (to give P1f) and finally a Sonogashira coupling with THS-acetylene. This sequence of deprotection and re-protection is required since bromination of the analogue of $\mathbf{P} \mathbf{1 a}[\mathbf{Z n}]$ with TMS protecting groups gives a complex mixture of products. Selective removal of the TMS groups of $\mathbf{P} \mathbf{1 g}$ to form $\mathbf{P} \mathbf{1 h}$ followed by coupling in the presence of T6 gave the targeted 6-porphyrin nanoring-template complex in $10 \%$ yield (c-P6a $\cdot \mathbf{T 6}$, Scheme $2 \mathrm{~b}$ ). It is crucial that T6 is removed from this unsymmetrical nanoring, to enable free rotation of the porphyrin units, because the template-complex probably exists as a mixture of stereoisomers with the THS-acetylene substituents pointing is different directions. Template removal was achieved with the ligand 1,4diazabicyclo[2.2.2] octane (DABCO). ${ }^{[74]}$ Finally, removal of the THS groups gave $\mathbf{c}$-P6b, which was subjected to palladium-catalyzed oxidative coupling under high-dilution conditions $(45 \mu \mathrm{M})$. The product was purified by recycling gel permeation chromatography (GPC) to yield $\boldsymbol{t}$-P12 in $10 \%$ overall yield from $\boldsymbol{c}$-P6a (Scheme $2 b$ ).
t-P12 prepared via the ring-stacking route (Scheme 2b) was fully characterized by ${ }^{1} \mathrm{H}$ NMR, UV-vis-NIR spectroscopy and MALDI-ToF analysis (see Supplementary Information) and could conveniently be compared to

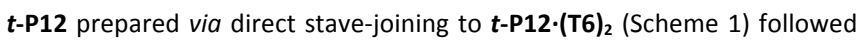
by treatment of $\boldsymbol{t}-\mathbf{P 1 2} \cdot(\mathrm{T6})_{2}$ with $\mathrm{DABCO}$ to remove the template. The template-directed stave-joining route to $\boldsymbol{t}$-P12 is better yielding (31\% yield of $\boldsymbol{t}$-P12·(T6) $)_{2}$ from $\mathbf{l - P 2 b}$ followed by $86 \%$ yield in the template-removal step) than the ring-stacking route to $\boldsymbol{t}$-P12 (10\% over the last two steps of THS removal on $\boldsymbol{c}$-P6a followed by coupling of $\boldsymbol{c}$-P6b to $\boldsymbol{t}$-P12) and it requires less protecting group manipulation. Hence stave-joining is the best strategy to access the 12-porphyrin nanotube. The ring-stacking strategy however, could provide access to longer nanotubes, if the capping 6-porphyrin nanoring is coupled to a central ring, which would circumvent the laborious preparation of increasingly long porphyrin oligomers that is required for (sequential or direct) stave-joining synthesis. This central ring requires acetylene moieties on both sides of the nanoring. Since this ring would not carry any solubilizing substituents, we expect it to have poor solubility. Despite the possible access to increasingly long porphyrin nanotubes via ring-stacking, we focused our efforts on the exploration of sequential and direct stave-joining strategies.

Stave-Joining Synthesis of $\boldsymbol{t}$-P18. Direct stave-joining in the presence of T6 using a hexa-acetylene substituted C4-linked porphyrin trimer (obtained by total removal of both the TIPS and CPDMS groups on I-P3b, Scheme 3 ) gave predominantly insoluble polymer rather than $t$-P18.(T6) $)_{3}$, presumably due to irreversible mismatched coupling. Therefore, we adopted a sequential approach (Figure 1b) to target $t$-P18.(T6) $)_{3}$. This approach requires a porphyrin trimer carrying orthogonal acetylene protecting groups on the central and outer porphyrins, I-P3b (Scheme 3) to enable selective removal of the acetylene protecting groups on the central 
a)

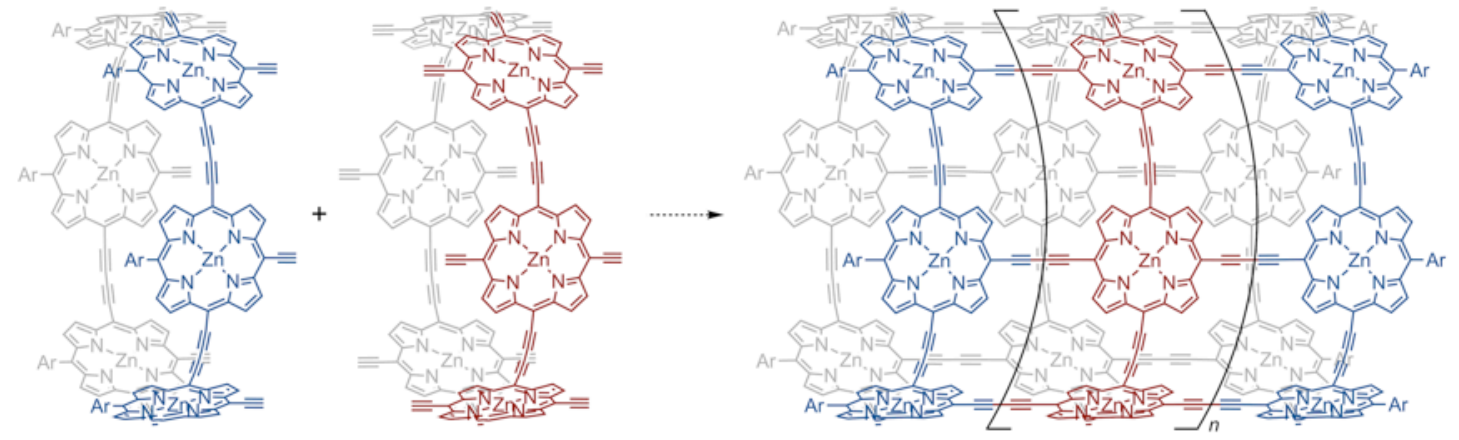

b)

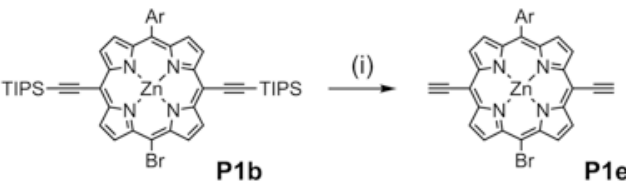

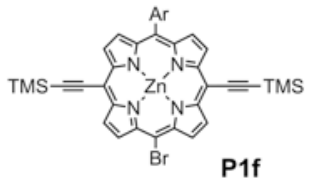

(iii)

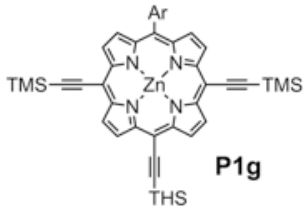
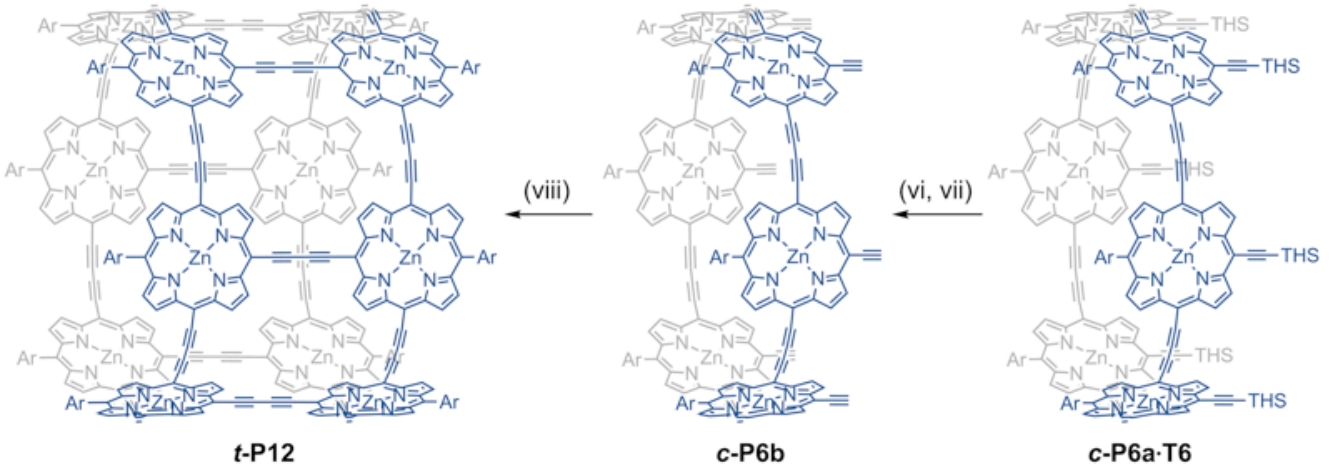

(v)

c-P6a-T6

Scheme 2. a) Ring-stacking strategy towards the synthesis of 6-ring based porphyrin nanotubes. b) Ring-stacking synthesis of $t$-P12. (i) TBAF, 98\%. (ii) LiHMDS, TMS-Cl, 82\%. (iii) $\mathrm{Pd}_{2} \mathrm{dba}_{3}, \mathrm{Cul}, \mathrm{PPh}_{3}$, THS-acetylene, 90\%. (iv) $\mathrm{K}_{2} \mathrm{CO}_{3}, 98 \%$. (v) T6, $\mathrm{Pd}\left(\mathrm{PPh}_{3}\right)_{2} \mathrm{Cl}_{2}, \mathrm{Cul}, 1,4$-benzoquinone, $\mathrm{N}, \mathrm{N}$-diisopropylamine, 10\%. (vi) DABCO, SEC, 89\%. (vii) TBAF (viii) $\mathrm{Pd}\left(\mathrm{PPh}_{3}\right)_{2} \mathrm{Cl}_{2}, \mathrm{Cul}, 1,4$-benqozuinone, $\mathrm{N}, \mathrm{N}$-diisopropylamine, $10 \%$ over two steps. Ar = 3,5-bis(trihexylsilyl)phenyl.

porphyrin and sequential template-directed stave-joining of $t$-P18·(T6 $)_{3}$ via its "pre-tube" complex, pt-P18-T6 (where pt denoting pre-tube, Scheme 3).

The porphyrin trimer I-P3a was prepared through statistical coupling of porphyrin monomers $\mathbf{P} \mathbf{1}$ and $\mathbf{P} \mathbf{1 d}$ in a 1:3 ratio which gave the desired porphyrin trimer in a reproducible $28 \%$ yield (from P1I) after purification by recycling GPC (Scheme 3). In this reaction, I-P2a was obtained as a useful side-product from homo-coupling of P1d (for the template-directed synthesis of $\boldsymbol{t}-\mathbf{P} \mathbf{1 2} \cdot(\mathbf{T 6})_{2}$, Scheme 1). Monomer P1l was prepared from P1, which was converted into its $\mathrm{Mg}$ complex $\mathbf{P} \mathbf{1 i}$ by treatment with $\mathrm{MgI}_{2}$ followed by bromination of the remaining meso-positions. Direct bromination of the $\mathrm{Zn}$ equivalent of P1i was avoided as we had previously found that bromination of a zinc 5,15-dialkynyl porphyrin leads to significant amounts of bromination at the $\beta$-positions of the porphyrin and on the alkynes. ${ }^{[75,76]}$ The $\mathrm{Mg}$ ion could easily be removed through treatment with acid (to give $\mathbf{P} \mathbf{1} \mathbf{j}$ ) after which $\mathrm{Zn}$ was inserted (to give $\mathbf{P} \mathbf{1 k}$ ) followed by removal of the TIPS groups to give P1I (Scheme 3). Monomer P1d was prepared as discussed above (Scheme 1). I-P3b was obtained from I-P3a by Sonogashira cross-coupling with CPDMS-acetylene on the central porphyrin (Scheme 3).

Selective removal of the CPDMS groups on I-P3b with $\mathrm{K}_{2} \mathrm{CO}_{3}$ gave $\mathbf{I -}$ P3c, which was subjected to palladium-catalyzed oxidative coupling in the presence of T6 to give the "pre-tube" complex pt-18-T6-a in 7\% yield. The low yield in this reaction presumably originates from competing nonconstructive binding-modes of the porphyrin trimer to the template (Figure 3a).

Removal of the TIPS groups on the 12 outer porphyrins of $p$ t-P18-T6-a to give $\boldsymbol{p t}$-P18-T6-b, and subjecting the latter to the same palladiumcatalyzed oxidative homo-coupling conditions in the presence of T6, was carried out to convert the highly pre-organized "pre-tube" complex to the target $t$-P18·(T6) $)_{3}$. During the reaction, the color of the solution changed from dark red to deep pink, in line with previous observations of nanotube formations. ${ }^{[60]}$ Reaction progress was monitored by UV-vis-NIR spectroscopy and when no further change was observed, the reaction mixture was passed through a short $\mathrm{SiO}_{2}$ plug in toluene/1\% pyridine. Analysis by GPC and MALDI-ToF spectrometry indicated successful formation of $\boldsymbol{t}$-P18·(T6) $)_{3}$. Analytical GPC showed the formation of a major product with slightly longer retention time (retention time of $30.9 \mathrm{~min}$ ) than pt-P18-T6-a (30.5 $\mathrm{min})$. This indicates a reduction of the hydrodynamic radius, which is consistent with the formation of $t$-P18.(T6) from $p t-P 18 \cdot T 6-a$. Unfortunately, $t$-P18-(T6) $)_{3}$ was found to adsorb strongly onto the polystyrene stationary phase used in GPC, resulting in long tails to the GPC peaks and poor mass-recovery. These problems prevented us from purifying or isolating the final compound. 


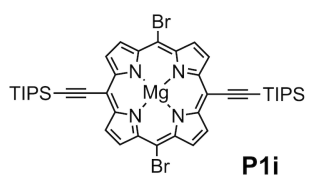

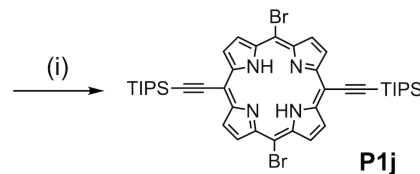

P1j

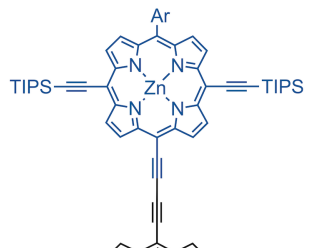

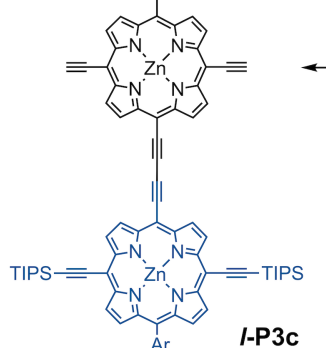

(vii)

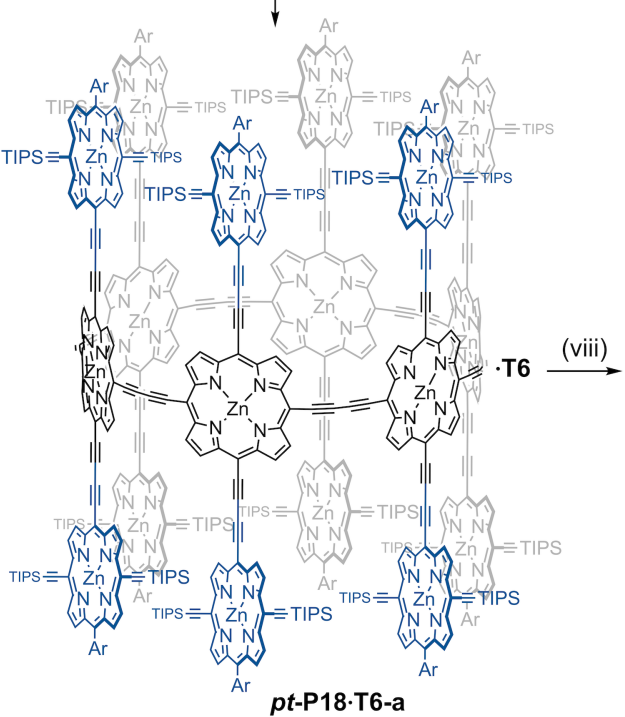

(vi)

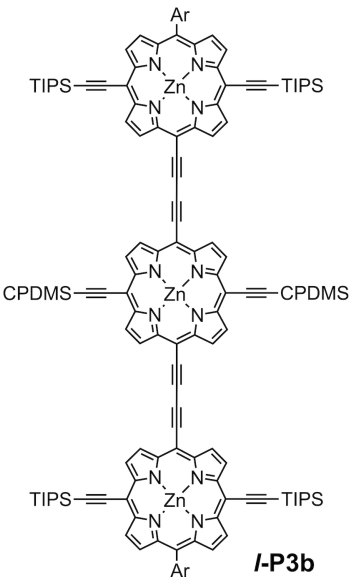

(ii) $P I P S=$

(v)

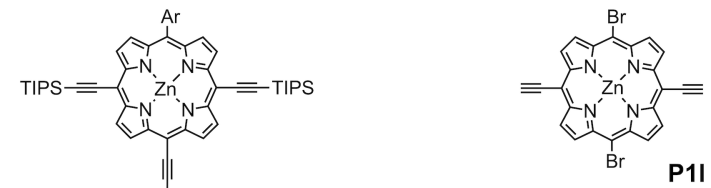

\section{.11}

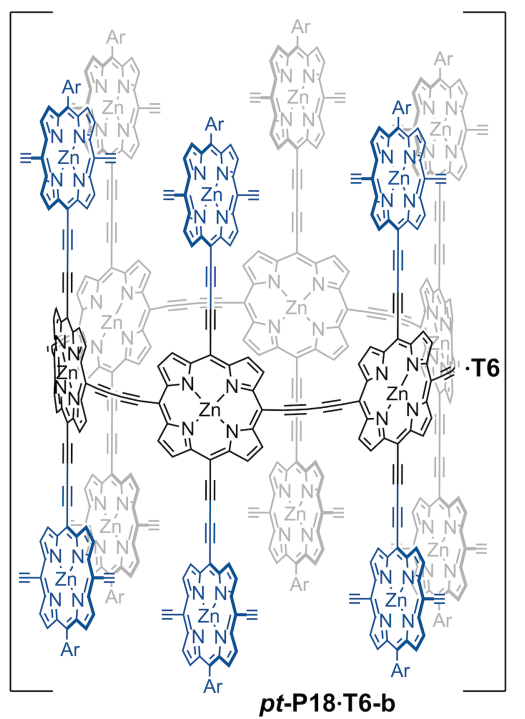

(iii)

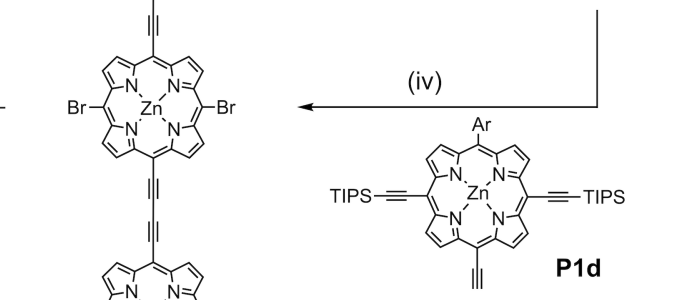

(ix)

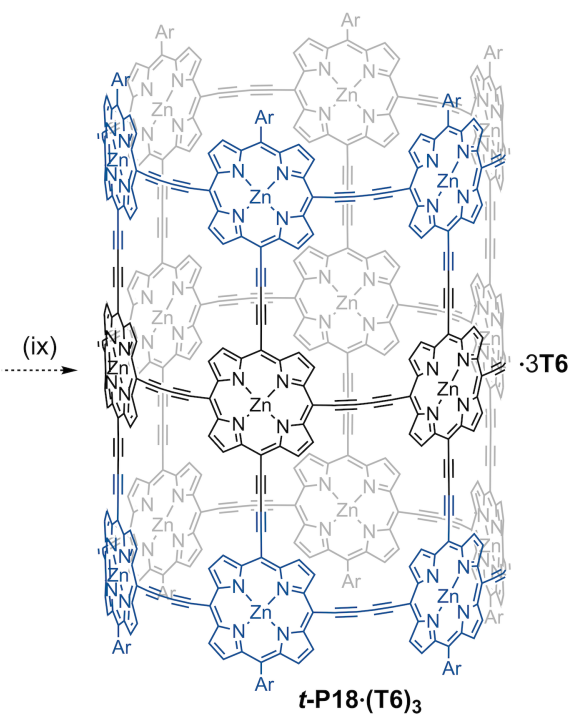

Scheme 3. Sequential template-directed stave-joining synthesis of $t$-P18·(T6) $)_{3}$. (i) NBS, 63\%. (ii) TFA, 91\%. (iii) $\left.\mathrm{Zn}_{(\mathrm{OAc}}\right)_{2} \cdot 2 \mathrm{H}_{2} \mathrm{O}, \mathrm{reflux}, 100 \%$. (iv) $\mathrm{TBAF}, 93 \%$. (iv) Pd(PPh $)_{2} \mathrm{Cl}{ }_{2}, \mathrm{Cul}$, 1,4-benzoquinone, 28\% (from P1l). (v) $\mathrm{Pd}_{2} \mathrm{dba}_{3}, \mathrm{Cul}_{2} \mathrm{PPh}_{3}$, CPDMS-acetylene, 97\%. (vi) $\mathrm{K}_{2} \mathrm{CO}_{3}, 100 \%$. (vii) T6, Pd(PPh $)_{2} \mathrm{Cl}_{2}, \mathrm{Cul}, 1,4-$ benzoquinone, 7\%. (viii) TBAF. (ix) T6, $\mathrm{Pd}\left(\mathrm{PPh}_{3}\right)_{2} \mathrm{Cl}_{2}$, Cul, 1,4-benzoquinone. Ar = 3,5-bis(trihexylsilyl)phenyl.

The modest yields in the synthesis of I-P3a and pt-P18-T6-a, prompted us to adapt our strategy towards 18-porphyrin nanotubes. A larger solubilizing group, bis(di-iso-butyloctadecylsilyl)phenyl, was introduced to improve the solubility of the final compound. Monoacetylene (C2) linked porphyrin oligomers were expected to give higher yields in the (cross-coupling) synthesis of the linear trimer. We also anticipated higher yields in the template-directed synthesis of pre-tube complex since the $\mathrm{C} 2$ link inhibits unfavorable binding to T6 template (Figure 3b). Furthermore, we expected C2-linked porphyrin nanotubes to exhibit enhanced electronic communication along the length of the nanotube, since $\mathrm{C} 2$-linked oligomers show red-shifted absorption and emission spectra, compared with C4-linked oligomers. ${ }^{[77]}$ a)

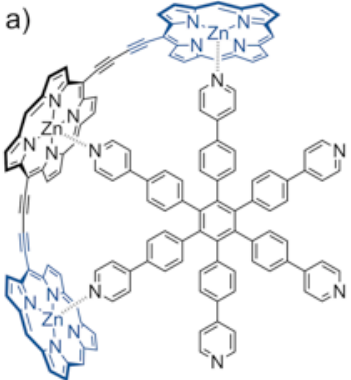

Figure 3. Schematic representation of the binding of (a) butadiyne-linked porphyrin

trimer and (b) mono-acetylenic porphyrin trimer to the T6 template. 10,20-meso-Aryl substituents omitted for clarity.

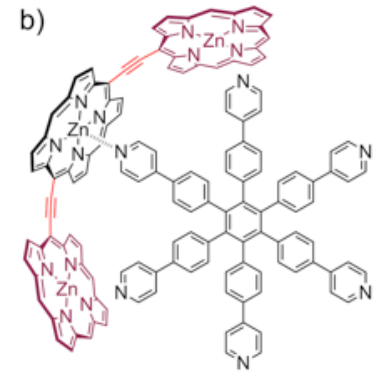

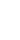



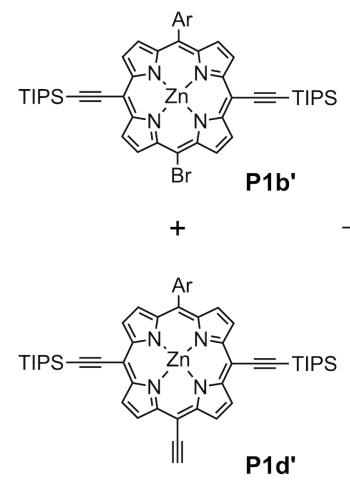

(i)

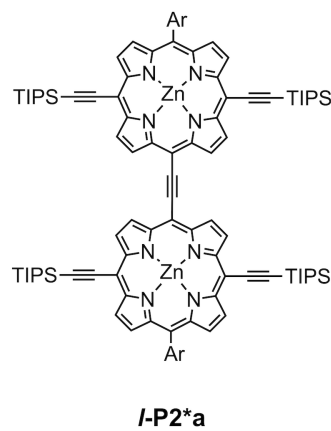

(ii)

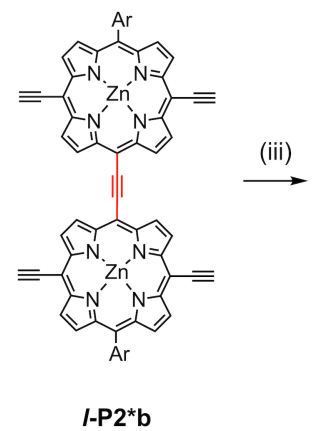

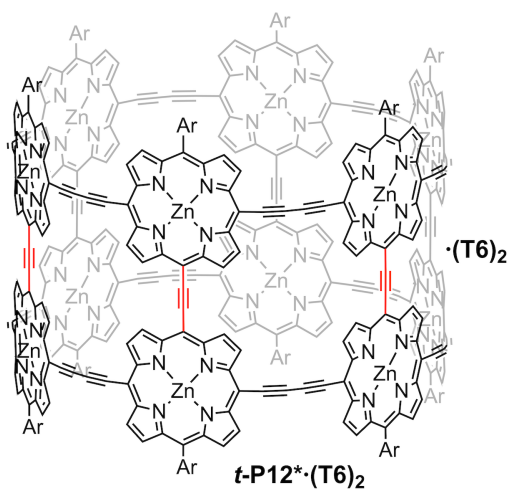

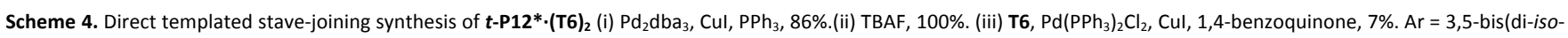
butyloctadecylsilyl)phenyl.

Stave-Joining Synthesis of $t-\mathrm{P} 12 * \cdot(\mathrm{T} 6)_{2}$ and $t-\mathrm{P} 18^{*} \cdot(\mathrm{T} 6)_{n}$. To examine the effect of a C2-linkage on the synthesis and properties of porphyrin nanotubes, we first prepared $t$-P12*.(T6 $)_{2}$; a 12 -porphyrin nanotube with C2-linkages between the conjoined 6-porphyrin nanorings. $t-P 12 * \cdot(T 6)_{2}$ was synthesized by template-directed stave-joining from C2-linked dimeric precursor I-P2*b (Scheme 4). At this stage, we introduced the larger solubilizing group 3,5-bis(di-iso-butyloctadecylsilyl)phenyl (denoted by ' in the $\mathbf{P} \mathbf{1 N}$ compound label). Monomers $\mathbf{P} \mathbf{1} \mathbf{b}^{\prime}$ and $\mathbf{P} \mathbf{1} \mathbf{d}$ ' were synthesized following an analogous synthetic route as their 3,5-bis(trihexylsilyl)phenyl solubilized counterparts P1b and P1d (Scheme 1) as described in the SI.

Sonogashira cross-coupling of $\mathbf{P} 1 \mathbf{b}^{\prime}$ and $\mathbf{P} 1 \mathbf{d}^{\prime}$ in 3:1 ratio gave I-P2*a in $86 \%$ yield (from P1d', Scheme 4). Excess P1b' was used to disfavor homo-coupling of P1d' and part of the excess P1b' was re-isolated during the purification. Homo-coupling of P1d' was not entirely prevented however, and I-P2'a was obtained as a minor byproduct, which could be separated from I-P2*a via extensive recycling GPC. Removal of the four TIPS groups on I-P2*a, followed by cyclo-oligomerization at room temperature in the presence of T6 gave $t-\mathbf{P 1 2} \cdot(\mathrm{T} 6)_{2}$ in $7 \%$ yield after purification by recycling GPC (Scheme 4). The modest yield in this reaction might arise to some extent from the requirement of the porphyrins across the mono-acetylene link to adopt a (close to) co-planar conformation. We found that higher yields were obtained when the reaction was performed at elevated temperature $\left(65^{\circ} \mathrm{C}\right)$ and reaction times were shorter $(2 \mathrm{~h})$. However, sharp ${ }^{1} \mathrm{H}$ NMR spectra of $t-\mathbf{P 1 2} * \cdot(\mathrm{T} 6)_{2}$ were obtained only when the reaction was performed at $25^{\circ} \mathrm{C}$ ( $6 \mathrm{~h}$ reaction time). Presumably, at higher temperatures defective structures are formed with sizes very similar to the target compound which elute with the target compound on recycling GPC.

The torsion angle between the mean planes of the two porphyrin units in C2-linked porphyrin dimers has been a topic of debate. Computational studies predict that C2-linked porphyrin dimers adopt a conformation with a dihedral angle of approximately $\theta=35^{\circ}$ in the gas phase, to alleviate the $\mathrm{H}-\mathrm{H}$ clash across the link while still allowing for substantial $\pi$-overlap. ${ }^{[0,77-80]}$ However, the high symmetry deduced from the NMR spectra of C2-linked porphyrin nanorings suggests that the steric congestion creates only a small barrier at room-temperature in solution. ${ }^{[70]}$ Therien and Anderson have reported similar observations on crystal structures of C2-linked porphyrin dimers in which the mean planes of the porphyrin units are (essentially) parallel. ${ }^{[71,81]}$ We envision that in the cyclooligomerization this repulsion, in combination with the enforced coplanarity by the T6 template, may account for the relative low yield in the synthesis of $\boldsymbol{t}-\mathbf{P 1 2} *(\mathbf{T 6})_{2}$ from $\mathbf{I - P 2} * \mathbf{b}$, compared to that of its C4-linked analogue $t$-P12·(T6) $)_{2}$ from $I-\mathbf{P} 2 \mathrm{~b}$.

To enable a sequential template-directed stave-joining synthesis of $\boldsymbol{t}$ P18*.(T6) $)_{3}$, we synthesized a C2-linked porphyrin trimer with orthogonal protecting groups on the central and outer porphyrins, I-P3*a (Scheme 5). The central porphyrin (P1m) was obtained through re-protection of monomer P1I using LiHMDS and TMS-chloride. Sonogashira cross-coupling of the porphyrin monomers $\mathbf{P} \mathbf{1} \mathbf{d}^{\prime}$ and $\mathbf{P} \mathbf{1} \mathbf{l}$ in a 3:1 ratio gave porphyrin trimer I-P3*a in 96\% yield (from P1I, Scheme 5). As a side product, I-P2'a was obtained via the homo-coupling of P1d', which could be separated from I-P3*a by recycling GPC. While some authors advocate copper-free conditions, ${ }^{[82,83]}$ and/or elevated temperatures for Sonogashira coupling of porphyrins, ${ }^{[70]}$ the cross-coupling syntheses of C2-linked oligomers I-P2*a (Scheme 4) and I-P3*a (Scheme 5) were performed under copper cocatalyzed conditions at room temperature. In both cases high yields were obtained, highlighting the synthetic advantage of using C2-linked oligomers over C4-linked oligomers, as the latter require statistical couplings that have intrinsically lower yield.

Selective removal of the TMS groups on the central porphyrin of $I$ P3*a with potassium carbonate in methanol/THF gave I-P3*b (Scheme 5). Cyclo-oligomerization of I-P3*b in the presence of T6 yielded "pre-tube" complex pt-P18*-T6-a (18\%) after purification by recycling GPC as a dark red solid. This yield is significantly higher than when pt-P18-T6-a was prepared from I-P3c (7\%, Scheme 3), presumably since in the case of the C2-linked porphyrin trimer there is less unfavorable wrapping around the template (Figure 3). Removal of the remaining TIPS groups on the outer porphyrins of pt-P18*.T6-a was carried out with TBAF in a $\mathrm{CH}_{2} \mathrm{Cl}_{2} / 10 \%$ pyridine solution. For the final palladium-catalyzed coupling to convert the highly pre-organized "pre-tube" complex to the 18-porphyrin nanotube, two conditions were examined. Under the first conditions, T6 was added to the reaction mixture to aid coupling of the remaining porphyrins. Under the second conditions, the reaction was performed in the absence of T6 in a $10 \%$ pyridine solution in $\mathrm{CHCl}_{3}$ to prevent aggregation of $\mathbf{p t - P 1 8 * - T 6 - b}$. 
Over the course of the reaction under both conditions, the mixture turned from deep red to deep pink, indicating porphyrin nanotube formation. The reactions were followed by UV-vis-NIR spectroscopy and when no further change was observed, the mixture was filtered over a short $\mathrm{SiO}_{2}$ plug, purified by size-exclusion chromatography (SEC, THF/1\% pyridine), and finally subjected to recycling GPC (THF/1\% pyridine).

The template-free conditions proved more efficient with an (analytical) yield of $7.1 \%$ of $t$-P18*.T6 versus $4.7 \%$ yield of $t$-P18*.(T6) obtained in the presence of T6 template. We suspect that aggregation of pt-P18*.T6-b, which can easily occur due to the flat and exposed $\pi$-surface, leads to cross-coupling, reducing the yield. In the absence of T6, pyridine can coordinate to the zinc centers on the outer side of the tube, hindering $\pi$-aggregation. In both cases, the material was found to adsorb onto the polystyrene stationary phase of the recycling GPC columns and only small amounts of material could be isolated.

We were curious whether the C2-link in I-P3* strongly encourages supramolecular pre-organization of the trimer to T6 template such that it enables the direct templated stave-joining synthesis of $t-P 18 * \cdot(T 6)_{3}$ from $I$ P3*c. We anticipated hexa-acetylene substitued I-P3C* (Scheme 5) could form a tubular supramolecular complex with T6 template; $\left(I-P 3^{*} \mathbf{c}\right)_{6} \cdot(T 6)_{3}$ (Figure 4a). UV-vis-NIR titrations show a clear end-point at 0.5 T6 to I-P3c* ratio (Figure 4b), which agrees with the formation of a $\left(I-\mathrm{P}^{*} * \mathbf{c}\right)_{6} \cdot(\mathrm{T} 6)_{3}$ supramolecular complex. A T6:I-P3c* ratio of 0.5 is also consistent with a

1:2 complex, however this would require a wrapping binding-mode of the porphyrin trimers to the template which is geometrically unlikely.

Removal of both the TIPS and TMS groups on I-P3*a with TBAF gave hexa-acetylene substituted I-P3*c which was subjected to palladiumcatalyzed cyclo-oligomerization in $\mathrm{CHCl}_{3}$ in the presence of $\mathbf{T 6}$ (Scheme 5). Over the course of the reaction the anticipated color change from deep red to deep pink was observed. The reaction was followed by UV-vis-NIR spectroscopy and when no further change was observed, the mixture was filtered over a short $\mathrm{SiO}_{2}$ plug, purified by SEC (THF/1\% pyridine), and finally $t$-P18*.(T6) $)_{3}$ was isolated by recycling GPC (THF/1\% pyridine). The

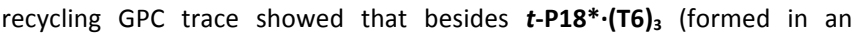
analytical yield of $1.7 \%$ ), a large amount of higher molecular weight material is formed. It seems that unfavorable mismatched coupling prevails, despite the apparent supramolecular pre-organization of I-P3*c in a tubular arrangement. The high extent of polymerization made it impossible to isolate sufficient material for further characterization of $\boldsymbol{t}$ P18*.(T6) ${ }_{3}$ prepared via this direct stave-joining approach. a)
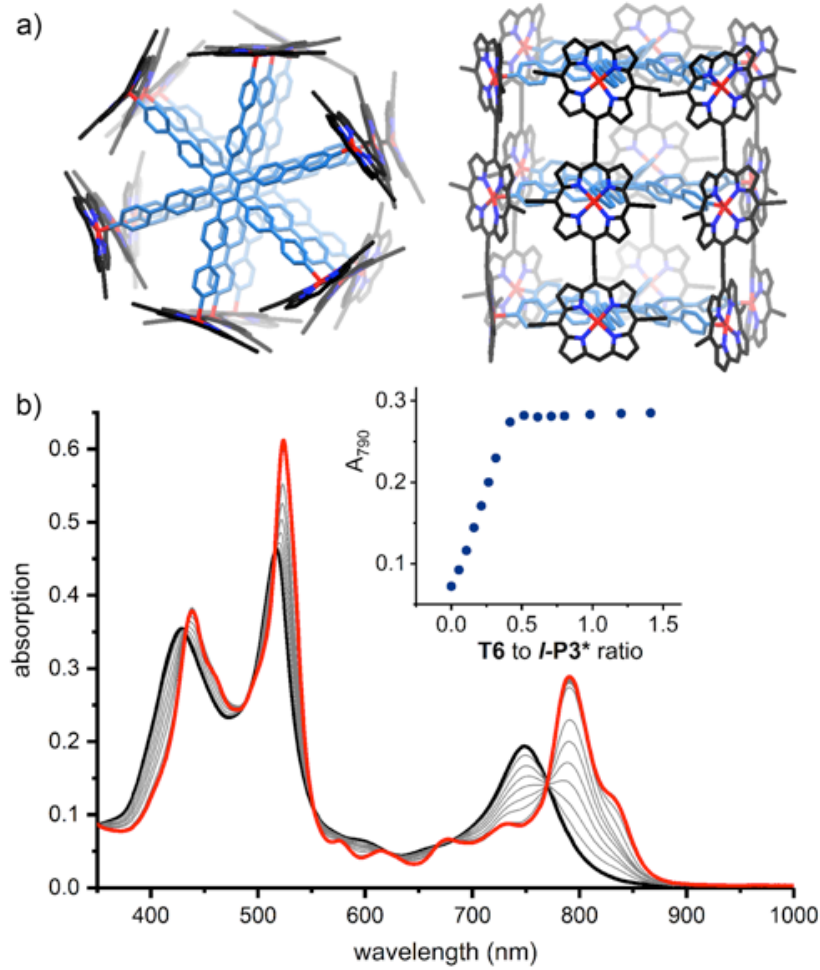

Figure 4. a) Calculated structure of $\left(I-\mathrm{P}^{*} \mathrm{C}\right)_{6} \cdot(\mathrm{T} 6)_{3}$ with hydrogen atoms omitted (modified MM2 force field, aryl groups bearing solubilizing side chains were omitted to simplify the calculations). b) UV-vis-NIR titration of I-P3*c with T6 (measured in $\mathrm{CHCl}_{3}$ at $298 \mathrm{~K}$, black trace: start of the titration, red trace: end of the titration). (insert) Absorption at $790 \mathrm{~nm}$ vs. T6/I-P3* mole ratio.

When we overlay and compare the analytical GPC traces and the corresponding UV-vis-NIR absorption spectra of $t$-P18*.T6 obtained via sequential stave-joining and $t$-P18*.(T6) $)_{3}$ obtained via direct stave-joining, it is evident that both strategies result in the same final product (Scheme 5, insert). To confirm that the compounds observed by analytical GPC are in fact the 18-porphyrin nanotube, pt-P18*-T6-a serves as a suitable reference. The "pre-tube" exhibits a shorter retention time due to its higher molecular weight and larger hydrodynamic diameter. Unfortunately, $\boldsymbol{t}$-P18* and its complexes with T6 are unstable as dry solids at room temperature. When a solution of the purified product is evaporated to dryness and redissolved, the formation of high molecular weight impurities is evident by analytical GPC. We found that the compound is stable when stored as a solution in THF/1\% pyridine. The instability of these compounds, and their challenging purification, make it difficult to carry out further studies on these giant porphyrin nanotubes.

${ }^{1} \mathbf{H}$ NMR Characterization. Regions of the ${ }^{1} \mathrm{H}$ NMR spectra of $\boldsymbol{t}$ P12*.(T6) $2, t$-P12·(T6) $2, t$-P12, pt-P18*.T6-a and $t$-P18*.T6 are compared in Figure 5. The ${ }^{1} \mathrm{H}$ NMR spectra are strikingly simple owing to their $D_{6 \mathrm{~h}}$ symmetry on the NMR timescale. The assignment of the aromatic protons is supported by NOESY and COSY experiments (the assignment of $\boldsymbol{t}$ P12.(T6) ${ }_{2}$ was published previously; ${ }^{[60]}$ see the SI for a detailed assignment of $t-\mathrm{P} 12 * \cdot(\mathrm{T} 6)_{2}$ and $\left.p t-\mathrm{P} 18^{*} \cdot \mathrm{T} 6-\mathrm{a}\right)$. 


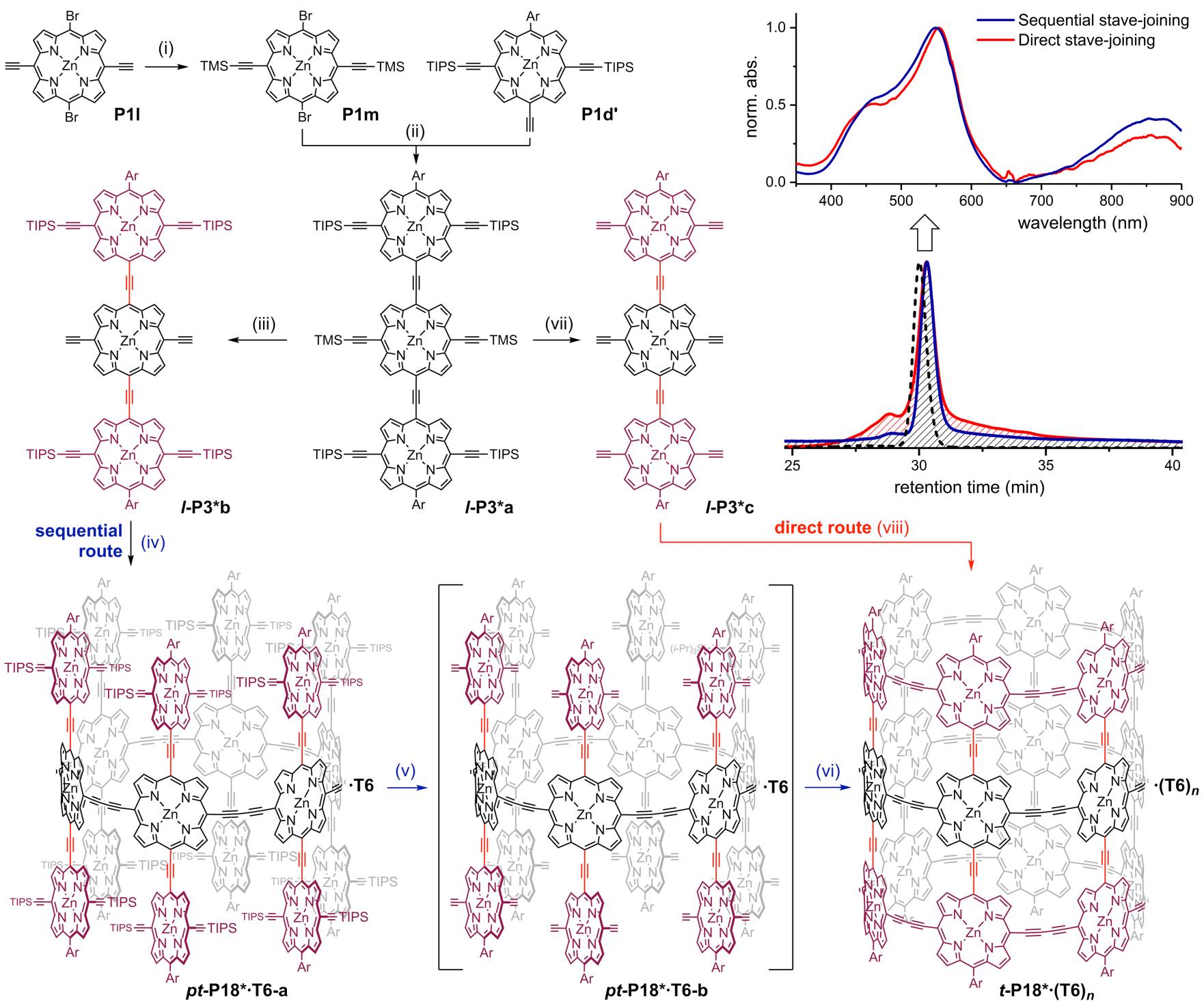

Scheme 5. Sequential and direct template-directed stave-joining synthesis of $t$-P18*.(T6) . (i) LiHMDS, then TMS-Cl, 53\%. (ii) $\mathrm{Pd}_{2} \mathrm{dba}_{3}, \mathrm{Cul}, \mathrm{PPh}_{3}, 96 \%$. (iii) $\mathrm{K}_{2} \mathrm{CO}_{3}, 90 \%$. (iv) $\mathrm{T6}$, $\mathrm{Pd}\left(\mathrm{PPh}_{3}\right)_{2} \mathrm{Cl}_{2}, \mathrm{Cul}$, 1,4-benzoquinone, 18\%. (v) TBAF. (vi) $\mathrm{Pd}\left(\mathrm{PPh}_{3}\right)_{2} \mathrm{Cl}_{2}, \mathrm{Cul}, 1,4$-benzoquinone, 7.1\% ${ }^{\#}$. (vii) TBAF, 98\%. (viii) T6, $\mathrm{Pd}(\mathrm{PPh})_{2} \mathrm{Cl} 2, \mathrm{Cul}, 1,4-$ benzoquinone, 1.7\% ${ }^{\#}$. Ar = 3,5bis(di-iso-butyloctadecylsilyl)phenyl. " denotes GPC analytical yield. Insert: Analytical GPC traces (THF/1\% pyridine, recorded at $500 \mathrm{~nm})$ of $\boldsymbol{t}$-P18*.(T6) ${ }_{3}$ (through direct stavejoining synthesis, red trace), $\boldsymbol{t}$-P18*-T6 (through sequential stave-joining synthesis, blue trace) and pt-P18*-T6-a (black dashed trace). UV-vis-NIR absorption spectra obtained from the analytical GPC at a retention time of $30.3 \mathrm{~min}$.

The signals of the templates in the template-complexes are strongly shielded by the porphyrin ring currents, especially the $\alpha$-pyridyl protons closest to the porphyrin plane which resonate at about $3 \mathrm{ppm}$. The porphyrin $\beta$-pyrrole proton signals show a similar pattern throughout, with the most significant divergence being proton a on $t-P 12 * \cdot(T 6)_{2}$ which is shifted $0.7 \mathrm{ppm}$ downfield compared to the analogous proton in $\boldsymbol{t}$ P12·(T6) 2 (10.7 ppm versus 10.0 ppm, respectively) (Figure 5a and Figure $5 b)$. This implies that proton a in $t-\mathbf{P 1 2} *(\mathbf{T} 6)_{2}$ experiences stronger deshielding by the ring currents of the two porphyrins across the C2-link. There are two signals for the ortho-aryl protons $0^{\prime} / \mathrm{o}$ of $t-\mathrm{P} 12 * \cdot(\mathrm{T} 6)_{2}$ and $t$ $\mathbf{P 1 2} \cdot(\mathbf{T 6})_{\mathbf{2}}$ indicating that the inside and outside of the nanotube provide different environments. While for $\boldsymbol{t}-\mathbf{P} \mathbf{1 2} \cdot(\mathbf{T 6})_{2}$, protons $\mathbf{o}^{\prime} / \mathbf{o}$ and $\mathbf{p}$ can be resolved, in its template-free analogue $\boldsymbol{t}$-P12 proton o overlaps with $\mathbf{p}$ (Figure 5c). In pt-P18*.T6-a, the outer porphyrins can freely rotate which render $\mathbf{o}^{\prime} / \mathrm{o}$ equivalent on the NMR timescale (Figure $5 \mathrm{~d}$ ).
t-P18*.T6 gives rise to a broad ${ }^{1} \mathrm{H}$ NMR spectrum (Figure 5e). However, in the aromatic region of the spectrum, signals for the $\beta$ - and aryl-protons can be distinguished. The unresolved $\beta$-proton signals of $\boldsymbol{t}$ P18*.T6 resonate at a chemical shift that is similar to the $\beta$-protons in $\boldsymbol{t}$ P12*.(T6) 2 , and further downfield than the analogous protons in ptP18*.T6-a. Furthermore, a broad signal at $8.1-7.8 \mathrm{ppm}$ can be distinguished which presumably corresponds to the ortho and para aryl protons. A possible explanation for the broad ${ }^{1} \mathrm{H}$ NMR spectrum is that the material exhibits some open-shell diradical character, as was recently observed for rylene nanoribbons. ${ }^{[84-86]}$ Another factor may be formation of $\pi-\pi$-stacked aggregates, ${ }^{[87]}$ which typically causes broadening of the NMR spectrum. ${ }^{[88-90]}$ The observation of extremely broad ${ }^{1} \mathrm{H}$ NMR spectra has been reported for other very large $\pi$-systems. ${ }^{[91]}$

Optical Properties. In general, the cancellation of the transition dipole moments in a symmetrical circular $\pi$-conjugated macrocycle makes 
the transition to the lowest electronic excited state symmetry-forbidden. Emission from this first excited state becomes partially allowed through vibronic coupling with higher excited states, known as Herzberg-Teller coupling. ${ }^{[66,70,74]}$ This phenomenon is manifested in a low fluorescence quantum yield since the slow radiative $S_{1}-S_{0}$ transition is competing with non-radiative decay pathways, as well as a red-shifted fluorescence, as the vibronic coupling shifts the emission to lower energies. Removing the templates from a cyclic porphyrin nanostructure enables more conformational freedom, breaks the symmetry and hence increases the fluorescence quantum yield. In Figure 6, we compare the absorption and emission spectra and fluorescence quantum yields of $t-P 12 * \cdot(T 6)_{2}, t-$ $\mathrm{P} 12 \cdot(\mathrm{T} 6)_{2}, t-\mathrm{P} 12$ and $t-\mathrm{P} 18^{*} \cdot(\mathrm{T} 6)_{\mathrm{n}}$
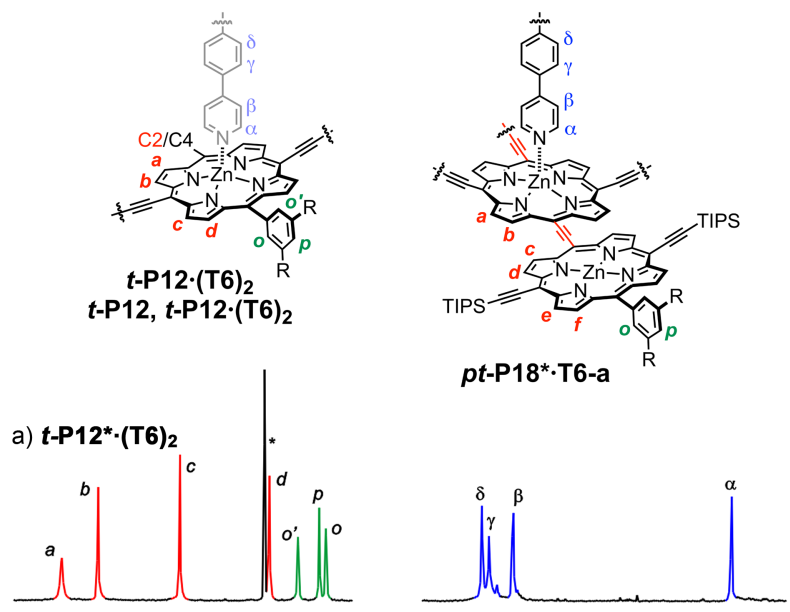

b) $t-P 12 \cdot(T 6)_{2}$
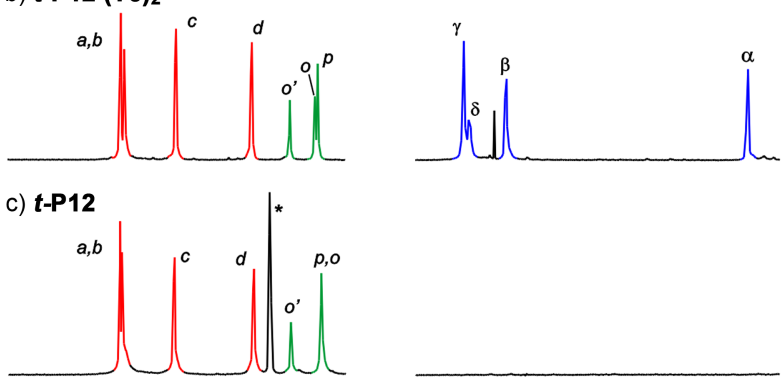

d) pt-P18*:T6-a

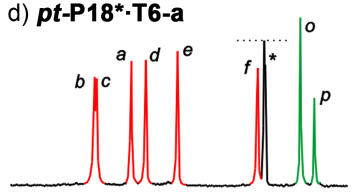

e) $t-P 18^{*} \cdot$ T6
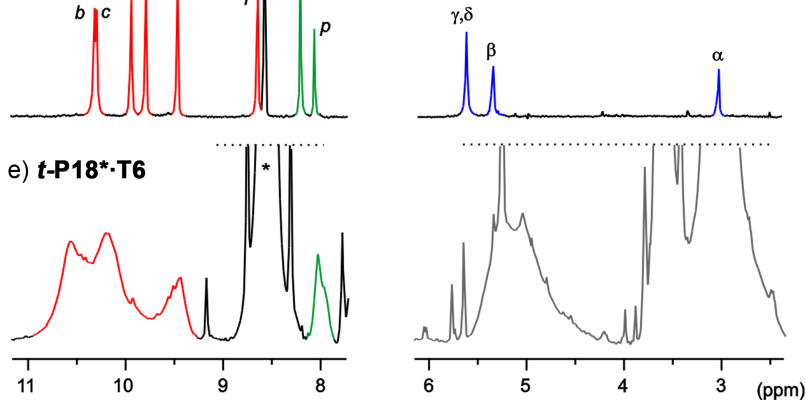

Figure 5. Region of the ${ }^{1} \mathrm{H}$ NMR spectra $\left(400 \mathrm{MHz} \mathrm{CDCl}_{3}\left(+1 \%\right.\right.$ pyridine- $\left.\mathrm{d}_{5}\right), 298 \mathrm{~K}$ ) of $\boldsymbol{t}$ P12*.(T6) ${ }_{2}, t$-P12·(T6) ${ }_{2}, t$-P12, pt-P18*-T6-a, and $t$-P18*.T6. $\beta$-proton signals (red), aryl-proton signals (green), and template-proton signals (blue) are labeled accordingly. $*$ = pyridine residual signal.

C2-linked 12-porphyrin nanotube $t$-P12*.(T6) ${ }_{2}$ displays a bathochromic shift in absorption of $40 \mathrm{~nm}$ compared to its C4-linked analogue $t$-P12·(T6) $)_{2}$, as well as a lower fluorescence quantum yield (Figure
6). These differences indicate increased conjugation over the chromophore and enhanced rigidity of $t-P 12 * \cdot(T 6)_{2}$. The high rigidity of porphyrin nanotubes is apparent when comparing the photophysical properties of the C4-linked 12-porphyrin nanotubes with and without template, $\boldsymbol{t}$ $\mathbf{P} 12 \cdot(\mathrm{T} 6)_{2}$ and $\boldsymbol{t}$-P12, respectively. $\boldsymbol{t}$-P12 displays a blue-shifted absorbance and loss of vibronic structure in the $Q$ band $(700-900 \mathrm{~nm})$, as well as a slightly higher fluorescence quantum yield $\left(\phi_{f}=0.26 \%\right)$ compared to $t$ $\mathbf{P 1 2} \cdot(\mathrm{T6})_{2}\left(\phi_{\mathrm{f}}=0.22 \%\right)$. These differences are much less pronounced than those previously observed for a 6-porphyrin nanoring, c-P6, and 6porphyrin nanoring-template complex, $\mathbf{c - P 6 \cdot T 6 , ~ f o r ~ w h i c h ~ t h e ~ f l u o r e s c e n c e ~}$ quantum yields were $0.42 \%$ and $1.99 \%$, respectively. ${ }^{[70]}$ The high intrinsic rigidity of porphyrin nanotubes prevents significant desymmetrization in the absence of the T6 and hence the transition to the lowest electronic excited state is still mostly symmetry-forbidden, evident from the small difference in fluorescence quantum yield between the template-complex and the template-free nanotube. The absorbance of $t$-P18*.T6 shows an unusually broad and undefined $Q$ band (Figure 6). The absorbance and emission of $t$-P18*.T6 are red-shifted compared to $t$-P12*.(T6) ${ }_{2}$ and $t$ P18*.T6 has a low fluorescence quantum yield of $0.08 \%$. These optical properties indicate an effective extension of the $\pi$-conjugated system and high conformational rigidity of $\boldsymbol{t}-\mathrm{P} 18^{*} \cdot \mathrm{T6}$.

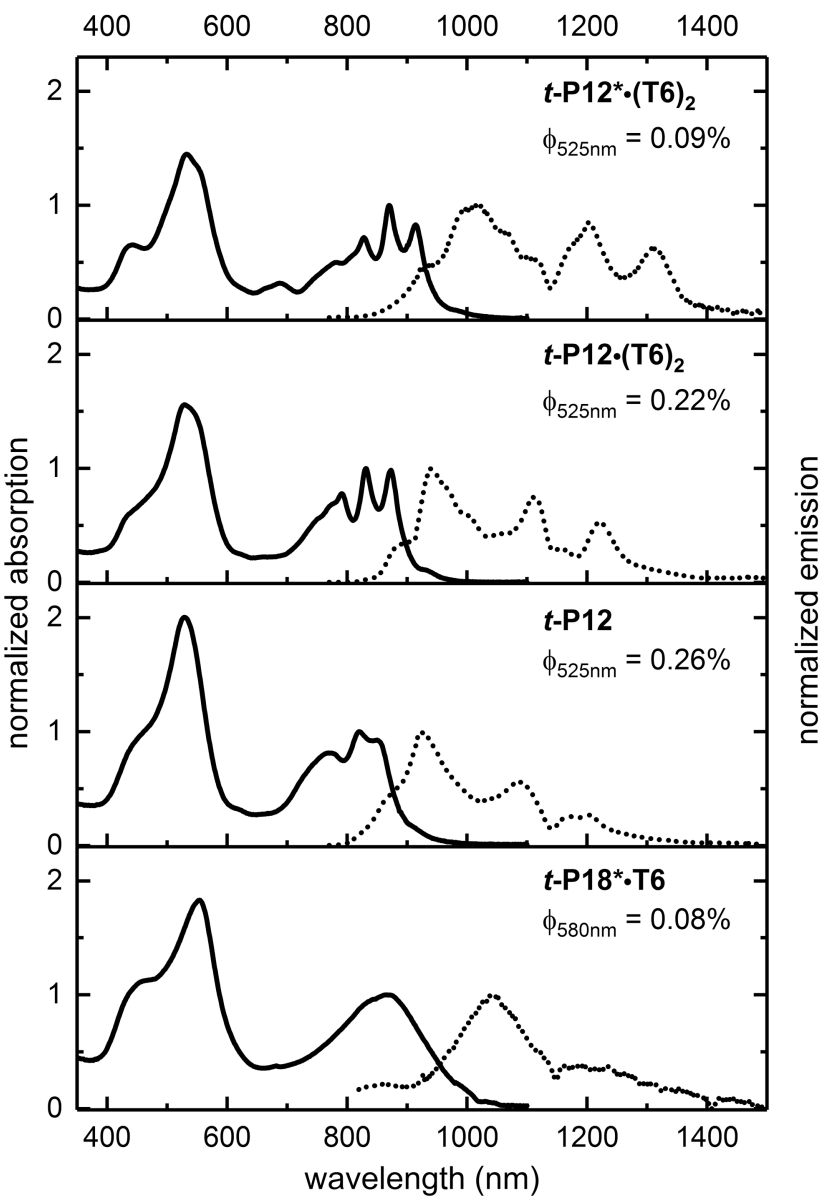

Figure 6. Normalized steady-state absorption (solid lines) and emission (dashed lines) of $\boldsymbol{t}$-P12*(T6) $)_{2}, \boldsymbol{t}$-P12·(T6) ${ }_{2}\left(\lambda_{\text {exc }}=525 \mathrm{~nm}\right.$, measured in toluene at $\left.298 \mathrm{~K}\right), \boldsymbol{t}-\mathbf{P} 12,\left(\lambda_{\text {exc }}=\right.$ $525 \mathrm{~nm}$, measured in toluene/1\% pyridine at $298 \mathrm{~K})$ and $\boldsymbol{t}$-P18*.T6 $\left(\lambda_{\mathrm{exc}}=580 \mathrm{~nm}\right.$, measured in $\mathrm{CHCl}_{3} / 1 \%$ pyridine at $298 \mathrm{~K}$ ). 
Molecular Modeling and Electronic Structure Calculations. Recent computational studies on infinite and discrete porphyrin nanotubes demonstrated that their electronic properties exhibit strong variations with the number of linking carbon atoms $(\mathrm{CO} / \mathrm{C} 2 / \mathrm{C} 4){ }^{[92]}$ and nanotube diameter. ${ }^{[93]}$ Density function theory (DFT) calculations (B3LYP/6-31G* with Grimme's D3 dispersion correction) were conducted to provide insight into the geometry and electronic structure of the porphyrin nanotubes discussed above.

The geometry optimization of $\boldsymbol{t}$-P18 was performed in $D_{6 \mathrm{~h}}$ symmetry. The optimized structure shows an undistorted tubular geometry (Figure 7a) analogous to the converged structure of $\boldsymbol{t}$-P12 which was published previously. ${ }^{[60]}$ The length of $\boldsymbol{t}-\mathbf{P} 18$ is $3.6 \mathrm{~nm}$ measured to the van der Waals surfaces of the outer $\beta$-pyrrole hydrogen atoms. The HOMO is delocalized over the entire conjugated system albeit with a higher coefficient on the central porphyrin nanoring. This effect is even more pronounced in the LUMO and fully reversed in the LUMO+1. The LUMO and LUMO+1 are practically degenerate and show negligible coefficients on the acetylene links between the conjoined rings (Figure 7b).

a)
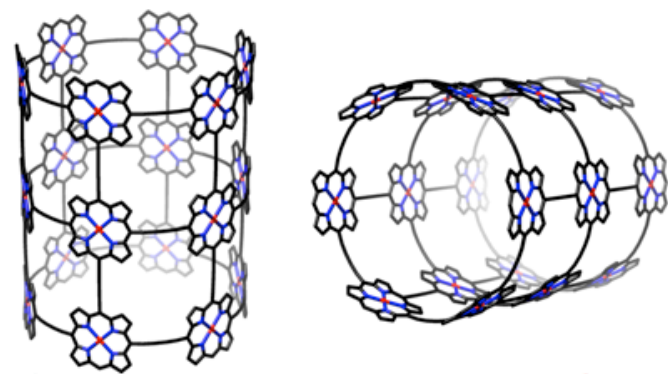

b)
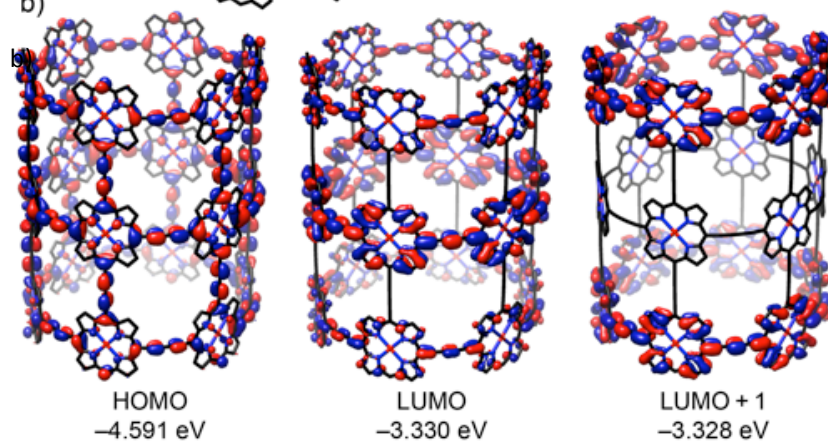

Figure 7. a) Optimized geometry of $\boldsymbol{t}$-P18 calculated at the B3LYP/6-31G* level of theory. b) HOMO, LUMO and LUMO+1 shown at a density isovalue of 0.008 au. Aryl groups were replaced with hydrogen atoms to simplify the calculations.

The geometry optimization of $\boldsymbol{t}$-P12* was performed in $S_{6}$ symmetry. The top view of the optimized structure shows the distortion of the nanotube, in which the porphyrins have adopted a twisted conformation with an average dihedral angle of $\theta=17.7^{\circ}$ (measured on opposite $\beta$ carbon atoms across the mono-acetylene link, Figure 8a). This conformation is presumably adopted to alleviate steric clash of the hydrogen atoms across the mono-acetylene link, as discussed above. The length of $\boldsymbol{t}-\mathbf{P} 12^{*}$ is $2.0 \mathrm{~nm}$ measured to the van der Waals surfaces of the outer $\beta$-pyrrole hydrogen atoms, which correlates perfectly with the $\mathrm{C} 2$ link compared to its C4 linked analogue $\mathbf{t}$-P12, for which the nanotube length was measured to be $2.3 \mathrm{~nm}$. The HOMO of $\boldsymbol{t}$-P12* is distributed over the entire $\pi$ system while the LUMO is localized over both rings, with negligible coefficients on the acetylene links between the rings (Figure 8b). This frontier orbital distribution resembles that of the C4-linked analogue $t$ P12. ${ }^{[60]}$ We were unable to calculate an optimized geometry for $\boldsymbol{t}$-P18* at the same level of theory as the other nanotubes (B3LYP/6-31G*). Twisting between C2-linked porphyrins reduces the symmetry of $\boldsymbol{t}$-P18* from $D_{6 \mathrm{~h}}$ to approximately $S_{6}$, making the calculation more demanding. Nonetheless, the diameter and length of this nanotube could be estimated to be $2.4 \mathrm{~nm}$ and $3.1 \mathrm{~nm}$, respectively, from a geometry optimized using less precise convergence criteria.

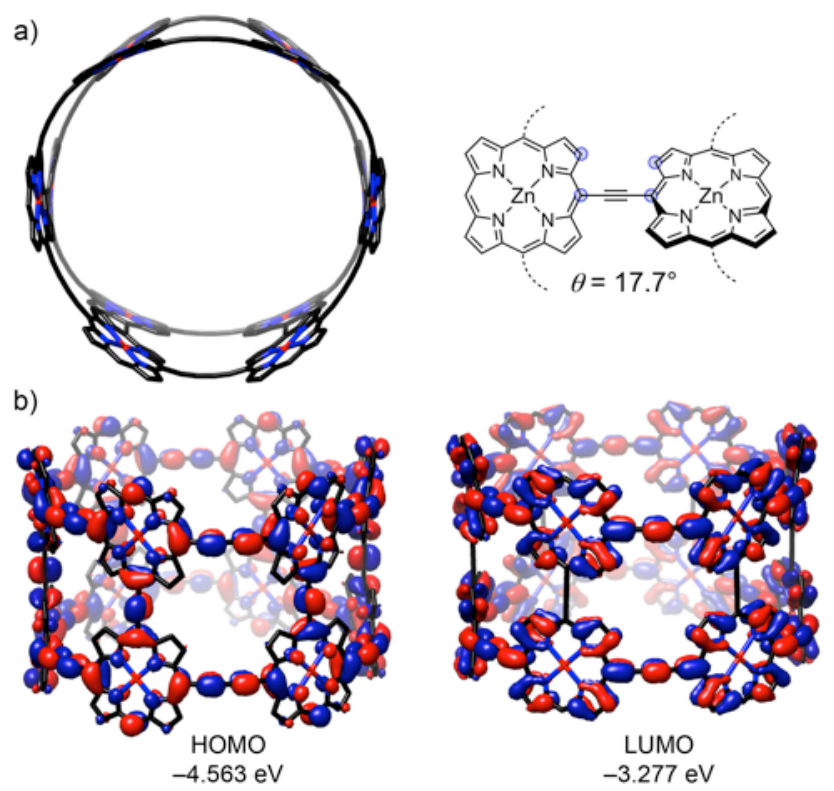

Figure 8. a) Optimized geometry of $\boldsymbol{t}$-P12* calculated at the B3LYP/6-31G* level of theory with a schematic depiction of the average dihedral angle across the C2-link. b) HOMO and LUMO shown at a density isovalue of $0.008 \mathrm{au}$. Aryl groups were replaced with hydrogen atoms to simplify the calculations.

\section{Conclusions}

We have examined different strategies to synthesize fully $\pi$ conjugated monodisperse porphyrin nanotubes with either butadiyne (C4) or acetylene ( $\mathrm{C} 2$ ) links between the conjoined 6-porphyrin nanorings. In the first strategy (stave-joining) the length of the nanotube is predefined by its linear porphyrin oligomer precursor. This strategy was used to make 12- and 18-porphyrin nanotubes $t$-P12·(T6) $)_{2}, t-P 12 * \cdot(T 6)_{2}$, and $t$-P18*(T6) $(n=1,3)$.

We also explored the covalent stacking of pre-formed 6-porphyrin nanorings and this approach was successful for the synthesis of $t-P 12$. This strategy for molecular nanotube formation is fundamentally different to previously published methods where non-covalent binding between the building blocks is established prior to covalent linkage. While covalent stacking could be a versatile approach to longer porphyrin nanotubes, extension of this strategy beyond the 12-porphyrin nanotube would require a second nanoring building block without aryl solubilizing groups, which is expected to have poor solubility. This strategy has not been further explored. 
Initially, we attempted to synthesize $\boldsymbol{t}-\mathbf{P} 18 \cdot(\mathrm{T6})_{3}$ through sequential template-directed stave-joining via its "pre-tube" complex, pt-P18-T6-a. Low yields, solubility problems and purification issues resulted in insufficient material to make this a viable route. We therefore introduced a larger solubilizing substituent and switched our attention to C2-linked porphyrin oligomer precursors. Nanotube $t$-P18*.(T6) $)_{n}$ could be synthesized via both sequential and direct stave-joining. In the sequential

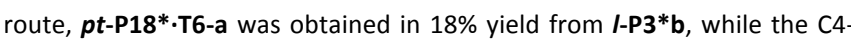
linked analogue, pt-P18-T6-a, was obtained in only 7\% yield from I-P3c, highlighting one of the benefits of using C2-linked linear oligomer precursors. The synthesis of $\boldsymbol{t}$-P18*.T6 via the sequential route proved most efficient (7.1\% yield). Remarkably, we found that hexa-acetylene substituted I-P3*c coupled in the presence of T6 does form $t-P 18^{*} \cdot(T 6)_{3}$, although mismatched coupling probably prevails, and only small amounts of the target compound are formed ( $1.7 \%$ yield). This is particularly striking since the analogous reaction using C4-linked porphyrin trimer gave exclusively insoluble polymer. This illustrates how a change in synthetic strategy as "simple" as the removal of 4 carbon atoms from the essential precursor, can make a dramatic difference. Purification of the 18-porphyrin tubes, $\boldsymbol{t}$-P18 and $\boldsymbol{t}$-P18*, was hampered by the tendency of these compounds to adsorb onto the polystyrene stationary phase used for GPC and to polymerize when solutions are evaporated to dryness, and by the broadness of their ${ }^{1} \mathrm{H}$ NMR spectra. In these respects, the 18-porphyrin tubes behave very differently from their 12-porphyrin analogues, perhaps because the central regions of the longer tubes are not shielded by bulky solubilizing groups. It is surprising that the main barrier to further research on these long porphyrin nanotubes is not the synthetic effort required to prepare the precursors, but the poor stability and chromatographic behavior of the final nanotubes.

Porphyrin nanotube $\boldsymbol{t}$-P18*.T6 is to the best of our knowledge the largest $\pi$-conjugated molecular nanotube to date, with dimensions similar to those of enzymes ( $\mathrm{Zn}-\mathrm{Zn}$ diameter of $2.4 \mathrm{~nm}$ and a length of $3.1 \mathrm{~nm}$ measured to the van der Waals surfaces of the outer $\beta$-pyrrole hydrogen atoms). The bottom-up synthetic approach to monodisperse molecular porphyrin nanotubes described here enables access to tailor-built monodisperse fully conjugated nanotubes with tunable properties and functionalities. Considering the current inaccessibility of uniform-diameter single-chirality CNTs, the strategies presented here are an important step towards well-defined molecular CNT analogues.

This article is dedicated to François Diederich in celebration of his inspirational work on $\pi$-conjugated porphyrin arrays ${ }^{[94-96]}$ and carbon-rich acetylenic scaffolds. ${ }^{[97-99]}$

\section{Experimental Section}

See Supplementary Material

\section{List of Abbreviations}

dba dibenzylideneacetone
CNT carbon nanotube

$\begin{array}{ll}\text { CPDMS } & \text { cyanopropyl-dimethylsilyl } \\ \text { DABCO } & \text { 1,4-diazabicyclo[2.2.2]octane } \\ \text { DDQ } & \text { 2,3-dichloro-5,6-dicyano-1,4-benzoquinone } \\ \text { GPC } & \text { gel permeation chromatography (high pressure, automated) } \\ \text { LiHMDS } & \text { lithium hexamethyldisilamide } \\ \text { ONT } & \text { organic nanotube } \\ \text { NBS } & \text { N-bromosuccinimide } \\ \text { SEC } & \text { size-exclusion chromatography (gravity, Biobeads) } \\ \text { TBAF } & \text { tetrabutlyammonium fluoride } \\ \text { THS } & \text { trihexylsilyl } \\ \text { TIPS } & \text { triisopropylsilyl } \\ \text { TMS } & \text { trimethylsilyl }\end{array}$

\section{Supplementary Material}

Supporting information for this article is available on the WWW under http://dx.doi.org/10.1002/MS-number. Synthetic procedures, characterization data, NMR assignments, and calculated geometries (PDF). Coordinate files for $\boldsymbol{t}$-P12, $\boldsymbol{t}$-P12* and $\boldsymbol{t}$-P18 (XYZ).

\section{Acknowledgements}

We thank the ERC (320969) for funding, the EPSRC UK national Mass Spectrometry Facility at Swansea University for MALDI spectra and the University of Oxford Advanced Research Computing Service (ARC, http://dx.doi.org/10.5281/zenodo.22558) for support. Isabell Gruebner is acknowledged for useful discussions. Michel Rickhaus is acknowledged for the design of Figure 1. We thank Joshua Sauer and Isabel Thomlinson for their help in making starting materials for the ring-stacking project.

\section{Author Contribution Statement}

R.H. performed the synthesis, prepared the materials and performed all characterizations, analysis and DFT calculations. R.H. and H.L.A. wrote the manuscript.

\section{References}

[1] S. lijima, 'Helical Microtubules of Graphitic Carbon', Nature 1991, 354, 5658.

[2] S. lijima, T. Ichihashi, 'Single-Shell Carbon Nanotubes of 1-nm Diameter', Nature 1993, 363, 603-605

[3] D. S. Bethune, C. H. Kiang, M. S. de Vries, G. Gorman, R. Savoy, J. Vazquez, R. Beyers, 'Cobalt-Catalysed Growth of Carbon Nanotubes with SingleAtomic-Layer Walls', Nature 1993, 363, 605-607.

[4] M. F. L. De Volder, S. H. Tawfick, R. H. Baughman, A. J. Hart, 'Carbon Nanotubes: Present and Future Commercial Applications', Science 2013, 339, 535-539.

[5] X. Jia, F. Wei, 'Advances in Production and Applications of Carbon Nanotubes', Top. Curr. Chem. 2017, 375, 1-35.

[6] L. Dai, D. W. Chang, J.-B. Baek, W. Lu, 'Carbon Nanomaterials for Advanced Energy Conversion and Storage', Small 2012, 8, 1130-1166.

[7] P. Avouris, 'Molecular Electronics with Carbon Nanotubes', Acc. Chem. Res. 
2002, 35, 1026-1034

[8]

M. Endo, T. Hayashi, Y.-A. Kim, 'Large-Scale Production of Carbon Nanotubes and Their Applications', Pure Appl. Chem. 2006, 78, 1703-1713. S. M. Bachilo, L. Balzano, J. E. Herrera, F. Pompeo, D. E. Resasco, R. B. Weisman, 'Narrow $(n, m)$-Distribution of Single-Walled Carbon Nanotubes Grown Using a Solid Supported Catalyst', J. Am. Chem. Soc. 2003, 125, 11186-11187.

[10] T. Kato, R. Hatakeyama, 'Direct Growth of Short Single-Walled Carbon Nanotubes with Narrow-Chirality Distribution by Time-Programmed Plasma Chemical Vapor Deposition', ACS Nano 2010, 4, 7395-7400.

[11] S. Hitosugi, W. Nakanishi, T. Yamasaki, H. Isobe, 'Bottom-up Synthesis of Finite Models of Helical $(n, m)$-Single-Wall Carbon Nanotubes', Nat. Commun. 2011, 2, 492-495.

[12] L. T. Scott, E. A. Jackson, Q. Zhang, B. D. Steinberg, M. Bancu, B. Li, 'A Short, Rigid, Structurally Pure Carbon Nanotube by Stepwise Chemical Synthesis', J. Am. Chem. Soc. 2012, 134, 107-110.

[13] S. Hitosugi, T. Yamasaki, H. Isobe, 'Bottom-up Synthesis and Thread-inBead Structures of Finite $(n, 0)$-Zigzag Single-Wall Carbon Nanotubes', J. Am. Chem. Soc. 2012, 134, 12442-12445.

[14] F. E. Golling, M. Quernheim, M. Wagner, T. Nishiuchi, K. Müllen, 'Concise Synthesis of 3D $\pi$-Extended Polyphenylene Cylinders', Angew. Chem. Int Ed. 2014, 53, 1525-1528.

[15] R. Sekiguchi, K. Takahashi, J. Kawakami, A. Sakai, H. Ikeda, A. Ishikawa, K. Ohta, S. Ito, 'Preparation of a Cyclic Polyphenylene Array for a Zigzag-Type Carbon Nanotube Segment', J. Org. Chem. 2015, 80, 5092-5110.

[16] G. Povie, Y. Segawa, T. Nishihara, Y. Miyauchi, K. Itami, 'Synthesis of a Carbon Nanobelt', Science 2017, 356, 172-175.

[17] J. S. Siegel, 'Allotropy by Design-Carbon Nanohoops', Science 2017, 356, 135-136.

[18] G. Povie, Y. Segawa, T. Nishihara, Y. Miyauchi, K. Itami, 'Synthesis and SizeDependent Properties of [12], [16], and [24]Carbon Nanobelts', J. Am. Chem. Soc. 2018, 140, 10054-10059.

[19] R. Jasti, J. Bhattacharjee, J. B. Neaton, C. R. Bertozzi, 'Synthesis, Characterization, and Theory of [9]-, [12]-, and [18]Cycloparaphenylene: Carbon Nanohoop Structures', J. Am. Chem. Soc. 2008, 130, 17646-17647. H. Omachi, Y. Segawa, K. Itami, 'Synthesis of Cycloparaphenylenes and Related Carbon Nanorings: A Step toward the Controlled Synthesis of Carbon Nanotubes', Acc. Chem. Res. 2012, 45, 1378-1389.

J. Xia, M. R. Golder, M. E. Foster, B. M. Wong, R. Jasti, 'Synthesis, Characterization, and Computational Studies of Cycloparaphenylene Dimers', J. Am. Chem. Soc. 2012, 134, 19709-19715.

H. Omachi, T. Nakayama, E. Takahashi, Y. Segawa, K. Itami, 'Initiation of Carbon Nanotube Growth by Well-Defined Carbon Nanorings', Nat. Chem. 2013, 5, 572-576.

[23] J. R. Sanchez-Valencia, T. Dienel, O. Gröning, I. Shorubalko, A. Mueller, M. Jansen, K. Amsharov, P. Ruffieux, R. Fasel, 'Controlled Synthesis of SingleChirality Carbon Nanotubes', Nature 2014, 512, 61-64.

[24] B. Liu, J. Liu, H. B. Li, R. Bhola, E. A. Jackson, L. T. Scott, A. Page, S. Irle, K. Morokuma, C. Zhou, 'Nearly Exclusive Growth of Small Diameter Semiconducting Single-Wall Carbon Nanotubes from Organic Chemistry Synthetic End-Cap Molecules', Nano Lett. 2015, 15, 586-595.

[25] Y. Segawa, H. Ito, K. Itami, 'Structurally Uniform and Atomically Precise Carbon Nanostructures', Nat. Rev. Mater. 2016, 1, 1-14.

[26] D. T. Bong, T. D. Clark, J. R. Granja, M. Reza Ghadiri, 'Self-Assembling Organic Nanotubes', Angew. Chem. Int. Ed. 2001, 40, 988-1011.

K. Tahara, Y. Tobe, 'Molecular Loops and Belts', Chem. Rev. 2006, 106,
[28]

B. Gong, Z. Shao, 'Self-Assembling Organic Nanotubes with Precisely Defined, Sub-Nanometer Pores: Formation and Mass Transport Characteristics', Acc. Chem. Res. 2013, 46, 2856-2866.

[29] I. W. Hamley, 'Peptide Nanotubes', Angew. Chem. Int. Ed. 2014, 53, 68666881.

[30] T. Shimizu, 'Self-Assembly of Discrete Organic Nanotubes', Bull. Chem. Soc. Jpn. 2018, 91, 623-668.

[31] Y. Xu, M. D. Smith, M. F. Geer, P. J. Pellechia, J. C. Brown, A. C. Wibowo, L. S. Shimizu, 'Thermal Reaction of a Columnar Assembled Diacetylene Macrocycle', J. Am. Chem. Soc. 2010, 132, 5334-5335.

[32] T. J. Hsu, F. W. Fowler, J. W. Lauher, 'Preparation and Structure of a Tubular Addition Polymer: A True Synthetic Nanotube', J. Am. Chem. Soc. 2012, 134, 142-145.

[33] J. M. Heo, Y. Kim, S. Han, J. F. Joung, S. hwa Lee, S. Han, J. Noh, J. Kim, S. Park, H. Lee, Y. M. Choi, Y. S. Jung, J. M. Kim, 'Chromogenic Tubular Polydiacetylenes from Topochemical Polymerization of Self-Assembled Macrocyclic Diacetylenes', Macromolecules 2017, 50, 900-913.

[34] M. R. Ghadiri, J. R. Granja, R. A. Milligan, D. E. McRee, N. Khazanovich, 'Self-Assembling Organic Nanotubes Based on a Cyclic Peptide Architecture', Nature 1993, 366, 324-327.

[35] D. Gauthier, P. Baillargeon, M. Drouin, Y. L. Dory, 'Self-Assembly of Cyclic Peptides into Nanotubes and then into Highly Anisotropic Crystalline Materials', Angew. Chem. Int. Ed. 2001, 40, 4635-4638.

[36] R. Chapman, M. Danial, M. L. Koh, K. A. Jolliffe, S. Perrier, 'Design and Properties of Functional Nanotubes from the Self-Assembly of Cyclic Peptide Templates', Chem. Soc. Rev. 2012, 41, 6023-6041.

Z. Liu, G. Liu, Y. Wu, D. Cao, J. Sun, S. T. Schneebeli, M. S. Nassar, C. A. Mirkin, J. F. Stoddart, 'Assembly of Supramolecular Nanotubes from Molecular Triangles and 1,2-Dihalohydrocarbons', J. Am. Chem. Soc. 2014, $136,16651-16660$.

[38] X. Wu, R. Liu, B. Sathyamoorthy, K. Yamato, G. Liang, L. Shen, S. Ma, D. K. Sukumaran, T. Szyperski, W. Fang, L. He, X. Chen, B. Gong, 'Discrete Stacking of Aromatic Oligoamide Macrocycles', J. Am. Chem. Soc. 2015, $137,5879-5882$.

[39] Q. Ji, H. T. M. Le, X. Wang, Y. S. Chen, T. Makarenko, A. J. Jacobson, O. Miljanic, 'Cyclotetrabenzoin: Facile Synthesis of a Shape-Persistent Molecular Square and Its Assembly into Hydrogen-Bonded Nanotubes', Chem. Eur. J. 2015, 21, 17205-17209.

[40] Y. Zhong, Q. Wang, Y. Yang, Z. Lu, L. He, B. Gong, 'Hexakis( $m$-Phenylene Ethynylene) Macrocycles with Multiple H-Bonding Side Chains and Modified Cavities: Altered Stacking Strength and Persistent Tubular Assembly', Org. Lett. 2016, 18, 2094-2097.

[41] G. D. Pantoş, P. Pengo, J. K. M. Sanders, 'Hydrogen-Bonded Helical Organic Nanotubes', Angew. Chem. Int. Ed. 2007, 46, 194-197.

[42] S. Ishihara, J. Labuta, W. Van Rossom, D. Ishikawa, K. Minami, J. P. Hill, K. Ariga, 'Porphyrin-Based Sensor Nanoarchitectonics in Diverse Physical Detection Modes', Phys. Chem. Chem. Phys. 2014, 16, 9713-9746. S. Lin, C. Diercks, Y. B. Zhang, N. Kornienko, E. M. Nichols, Y. Zhao, A. R. Paris, D. Kim, P. Yang, O. M. Yaghi, C. J. Chang, 'Covalent Organic Frameworks Comprising Cobalt Porphyrins for Catalytic $\mathrm{CO}_{2}$ Reduction in Water', Science 2015, 349, 1208-1213.

[44] N. Zhang, L. Wang, H. Wang, R. Cao, J. Wang, F. Bai, H. Fan, 'SelfAssembled One-Dimensional Porphyrin Nanostructures with Enhanced Photocatalytic Hydrogen Generation', Nano Lett. 2018, 18, 560-566.

[45] P. T. Smith, B. P. Benke, Z. Cao, Y. Kim, E. M. Nichols, K. Kim, C. J. Chang, 
'Iron Porphyrins Embedded into a Supramolecular Porous Organic Cage for Electrochemical $\mathrm{CO}_{2}$ Reduction in Water', Angew. Chem. Int. Ed. 2018, 57 9684-9688.

[46]

I. Hijazi, T. Bourgeteau, R. Cornut, A. Morozan, A. Filoramo, J. Leroy, V. Derycke, B. Jousselme, S. Campidelli, 'Carbon Nanotube-Templated Synthesis of Covalent Porphyrin Network for Oxygen Reduction Reaction', J. Am. Chem. Soc. 2014, 136, 6348-6354.

H. Jia, Z. Sun, D. Jiang, P. Du, 'Covalent Cobalt Porphyrin Framework on Multiwalled Carbon Nanotubes for Efficient Water Oxidation at Low Overpotential', Chem. Mater. 2015, 27, 4586-4593.

[48] R. F. Pasternack, P. R. Huber, P. Boyd, G. Engasser, L. Francesconi, E. Gibbs, P. Fasella, G. C. Venturo, L. D. Hinds, 'On the Aggregation of MesoSubstituted Water-Soluble Porphyrins', J. Am. Chem. Soc. 1972, 94, 45114517.

O. Ohno, Y. Kaizu, H. Kobayashi, 'J - aggregate Formation of a WaterSoluble Porphyrin in Acidic Aqueous Media', J. Chem. Phys. 1993, 99, 4128-4139.

A. D. Schwab, D. E. Smith, C. S. Rich, E. R. Young, W. F. Smith, J. C. de Paula, 'Porphyrin Nanorods', J. Phys. Chem. B 2003, 107, 11339-11345.

Z. Wang, C. J. Medforth, J. A. Shelnutt, 'Porphyrin Nanotubes by lonic SelfAssembly', J. Am. Chem. Soc. 2004, 126, 15954-15955.

Y. Wan, A. Stradomska, J. Knoester, L. Huang, 'Direct Imaging of Exciton Transport in Tubular Porphyrin Aggregates by Ultrafast Microscopy', J. Am. Chem. Soc. 2017, 139, 7287-7293.

H. L. Anderson, J. K. M. Sanders, 'Amine-Template-Directed Synthesis of Cyclic Porphyrin Oligomers', Angew. Chem. Int. Ed. 1990, 29, 1400-1403.

S. Anderson, H. L. Anderson, J. K. M. Sanders, 'Expanding Roles for Templates in Synthesis', Acc. Chem. Res. 1993, 26, 469-475.

J. Li, A. Ambroise, S. I. Yang, J. R. Diers, J. Seth, C. R. Wack, D. F. Bocian, D. Holten, J. S. Lindsey, 'Template-Directed Synthesis, Excited-State Photodynamics, and Electronic Communication in a Hexameric Wheel of Porphyrins', J. Am. Chem. Soc. 1999, 121, 8927-8940.

L. Yu, J. S. Lindsey, 'Rational Syntheses of Cyclic Hexameric Porphyrin Arrays for Studies of Self-Assembling Light-Harvesting Systems', J. Org Chem. 2001, 66, 7402-7419.

K. Y. Tomizaki, L. Yu, L. Wei, D. F. Bocian, J. S. Lindsey, 'Synthesis of Cyclic Hexameric Porphyrin Arrays. Anchors for Surface Immobilization and Columnar Self-Assembly', J. Org. Chem. 2003, 68, 8199-8207.

O. Mongin, A. Schuwey, M. A. Vallot, A. Gossauer, 'Synthesis of a Macrocyclic Porphyrin Hexamer with a Nanometer-Sized Cavity as a Model for the Light-Harvesting Arrays of Purple Bacteria', Tetrahedron Lett. 1999, 40, 8347-8350.

S. Rucareanu, A. Schuwey, A. Gossauer, 'One-Step Template-Directed Synthesis of a Macrocyclic Tetraarylporphyrin Hexamer Based on Supramolecular Interactions with a $C_{3}$-Symmetric Tetraarylporphyrin Trimer', J. Am. Chem. Soc. 2006, 128, 3396-3413.

P. Neuhaus, A. Cnossen, J. Q. Gong, L. M. Herz, H. L. Anderson, 'A Molecular Nanotube with Three-Dimensional $\pi$-Conjugation', Angew. Chem. Int. Ed. 2015, 54, 7344-7348.

P. S. Bols, H. L. Anderson, 'Template-Directed Synthesis of Molecular Nanorings and Cages', Acc. Chem. Res. 2018, 51, 2083-2092.

62] M. D. Peeks, C. E. Tait, P. Neuhaus, G. M. Fischer, M. Hoffmann, R. Haver, A. Cnossen, J. R. Harmer, C. R. Timmel, H. L. Anderson, 'Electronic Delocalization in the Radical Cations of Porphyrin Oligomer Molecular Wires', J. Am. Chem. Soc. 2017, 139, 10461-10471.

P. N. Taylor, J. Huuskonen, G. Rumbles, R. T. Aplin, E. Williams, H. L.
Anderson, G. Rumbles, E. Williams, H. L. Anderson, 'Conjugated Porphyrin Oligomers from Monomer to Hexamer', Chem. Commun. 1998, 909-910.

M. Hoffmann, J. Kärnbratt, M.-H. Chang, L. M. Herz, B. Albinsson, H. L. Anderson, 'Enhanced $\pi$-Conjugation Around a Porphyrin[6] Nanoring', Angew. Chem. Int. Ed. 2008, 47, 4993-4996.

[65] M. C. O'Sullivan, J. K. Sprafke, D. V Kondratuk, C. Rinfray, T. D. W. Claridge, A. Saywell, M. O. Blunt, J. N. O'Shea, P. H. Beton, M. Malfois, H. L. Anderson, 'Vernier Templating and Synthesis of a 12-Porphyrin Nano-Ring', Nature 2011, 469, 72-75.

[66] J. K. Sprafke, D. V. Kondratuk, M. Wykes, A. L. Thompson, M. Hoffmann, R. Drevinskas, W. H. Chen, C. K. Yong, J. Kärnbratt, J. E. Bullock, M. Malfois, M. R. Wasielewski, B. Albinsson, L. M. Herz, D. Zigmantas, D. Beljonne, H. L. Anderson, 'Belt-Shaped $\pi$-Systems: Relating Geometry to Electronic Structure in a Six-Porphyrin Nanoring', J. Am. Chem. Soc. 2011, 133, 17262-17273.

[67] L. Favereau, A. Cnossen, J. B. Kelber, J. Q. Gong, R. M. Oetterli, J. Cremers, L. M. Herz, H. L. Anderson, 'Six-Coordinate Zinc Porphyrins for TemplateDirected Synthesis of Spiro-Fused Nanorings', J. Am. Chem. Soc. 2015, 137, 14256-14259.

[68] J. Cremers, R. Haver, M. Rickhaus, J. Q. Gong, L. Favereau, T. D. W. Claridge, L. M. Herz, H. L. Anderson, 'Template-Directed Synthesis of a Conjugated Zinc Porphyrin Nanoball', J. Am. Chem. Soc. 2018, 140, 5352-5355.

[69] V. S.-Y. Lin, S. G. DiMagno, M. J. Therien, 'Highly Conjugated, Acetylenyl Bridged Porphyrins: New Models for Light-Harvesting Antenna Systems', Science 1994, 264, 1105-1111.

[70] M. Rickhaus, A. Vargas Jentzsch, L. Tejerina, I. Gruebner, M. Jirasek, T. D. W. Claridge, H. L. Anderson, 'Single-Acetylene Linked Porphyrin Nanorings', J. Am. Chem. Soc. 2017, 139, 16502-16505.

[71] M. J. Smith, I. M. Blake, W. Clegg, H. L. Anderson, 'Push-Pull Quinoidal Porphyrins', Org. Biomol. Chem. 2018, 16, 3648-3654.

[72] M. O. Senge, Y. M. Shaker, M. Pintea, C. Ryppa, S. S. Hatscher, A. Ryan, Y. Sergeeva, 'Synthesis of Meso-Substituted ABCD-Type Porphyrins by Functionalization Reactions', Eur. J. Org. Chem. 2010, 237-258.

[73] M. O. Senge, 'Stirring the Porphyrin Alphabet Soup - Functionalization Reactions for Porphyrins', Chem. Commun. 2011, 47, 1943-1960.

[74] M. Hoffmann, J. Kärnbratt, M. H. Chang, L. M. Herz, B. Albinsson, H. L. Anderson, 'Enhanced $\pi$ Conjugation Around a Porphyrin[6] Nanoring', Angew. Chem. Int. Ed. 2008, 47, 4993-4996.

[75] S. G. Wilson, H. L. Anderson, 'A Conjugated Triple Strand Porphyrin Array', Chem. Commun. 1999, 1, 1539-1540.

[76] T. E. O. Screen, K. B. Lawton, G. S. Wilson, N. Dolney, R. Ispasoiu, T. Goodson III, S. J. Martin, D. D. C. Bradley, H. L. Anderson, 'Synthesis and Third Order Nonlinear Optics of a New Soluble Conjugated Porphyrin Polymer', J. Mater. Chem. 2001, 11, 312-320.

[77] V. S.-Y. Lin, M. J. Therien, 'The Role of Porphyrin-to-Porphyrin Linkage Topology in the Extensive Modulation of the Absorptive and Emissive Properties of a Series of Ethynyl- and Butadiynyl-Bridged Bis- and Tris(Porphinato)Zinc Chromophores', Chem. Eur. J. 1995, 1, 645-651.

[78] I. V. Rubtsov, K. Susumu, G. I. Rubtsov, M. J. Therien, 'Ultrafast Singlet Excited-State Polarization in Electronically Asymmetric Ethyne-Bridged Bis[(Porphinato)Zinc(II)] Complexes', J. Am. Chem. Soc. 2003, 125, 26872696.

[79] P. N. Day, K. A. Nguyen, R. Pachter, 'Calculation of One-Photon and TwoPhoton Absorption Spectra of Porphyrins Using Time-Dependent Density Functional Theory', J. Chem. Theory Comput. 2008, 4, 1094-1106.

[80] L. Rintoul, S. R. Harper, D. P. Arnold, 'A Systematic Theoretical Study of the 
Electronic Structures of Porphyrin Dimers: DFT and TD-DFT Calculations on Diporphyrins Linked by Ethane, Ethene, Ethyne, Imine, and Azo Bridges', Phys. Chem. Chem. Phys. 2013, 15, 18951-18964.

[81]

T. V Duncan, P. R. Frail, I. R. Miloradovic, M. J. Therien, N. Carolina, 'Excitation of Highly Conjugated (Porphinato) Palladium(II) and (Porphinato) Platinum(II) Oligomers Produces Long-Lived, Triplet States at Unit Quantum Yield That Absorb Strongly over Broad Spectral Domains of the NIR', J. Phys. Chem. B 2010, 114, 14696-14702.

R. W. Wagner, J. Seth, S. I. Yang, D. Kim, D. F. Bocian, D. Holten, J. S. Lindsey, 'Synthesis and Excited-State Photodynamics of a Molecular Square Containing Four Mutually Coplanar Porphyrins', J. Org. Chem. 1998 $63,5042-5049$

W. Zeng, H. Phan, T. S. Herng, T. Y. Gopalakrishna, N. Aratani, Z. Zeng, H. Yamada, J. Ding, J. Wu, 'Rylene Ribbons with Unusual Diradical Character', Chem 2017, 2, 81-92. M. Abe, 'Diradicals', Chem. Rev. 2013, 113, 7011-7088.

[86] Z. Zeng, X. Shi, C. Chi, J. T. López Navarrete, J. Casado, J. Wu, 'Pro-Aromatic and Anti-Aromatic $\pi$-Conjugated Molecules: An Irresistible Wish to Be Diradicals', Chem. Soc. Rev. 2015, 44, 6578-6596.

M. Hutin, J. K. Sprafke, B. Odell, H. L. Anderson, T. D. W. Claridge, 'A Discrete Three-Layer Stack Aggregate of a Linear Porphyrin Tetramer: Solution-Phase Structure Elucidation by NMR and X-Ray Scattering', J. Am. Chem. Soc. 2013, 135, 12798-12807.

[88] S. Hiroto, A. Osuka, 'Meso-Alkyl-Substituted Meso-Meso Linked Diporphyrins and Meso-Alkyl-Substituted Meso-Meso, $\beta-\beta, \beta-\beta$ Triply Linked Diporphyrins', J. Org. Chem. 2005, 70, 4054-4058.

[89] D. Myśliwiec, B. Donnio, P. J. Chmielewski, B. Heinrich, M. Stepień, 'Peripherally Fused Porphyrins via the Scholl Reaction: Synthesis, SelfAssembly, and Mesomorphism', J. Am. Chem. Soc. 2012, 134, 4822-4833.

H. L. Anderson, 'Conjugated Porphyrin Ladders', Inorg. Chem. 1994, 33, 972-981.

Q. Chen, L. Brambilla, L. Daukiya, K. S. Mali, S. De Feyter, M. Tommasini, K. Müllen, A. Narita, 'Synthesis of Triply Fused Porphyrin-Nanographene Conjugates', Angew. Chem. Int. Ed. 2018, 57, $11233-11237$.

V. Posligua, A. Aziz, R. Haver, M. D. Peeks, H. L. Anderson, R. Grau-Crespo, 'Band Structures of Periodic Porphyrin Nanostructures', J. Phys. Chem. C 2018, 122, 23790-23798.

[93] S. I. Allec, N. V. Ilawe, B. M. Wong, 'Unusual Bandgap Oscillations in Template-Directed $\pi$-Conjugated Porphyrin Nanotubes', J. Phys. Chem. Lett. 2016, 7, 2362-2367.

[94] J. Wytko, V. Berl, M. McLaughlin, R. R. Tykwinski, M. Schreiber, F. Diederich, C. Boudon, J.-P. Gisselbrecht, M. Gross, 'Porphyrin-[(E)-1,2Diethynylethene] Scaffolding: Synthesis and Optical and Electrochemical Properties of Multinanometer-Sized Porphyrin Arrays', Helv. Chim. Acta 1998, 81, 1964-1977.

F. Cheng, S. Zhang, A. Adronov, L. Echegoyen, F. Diederich, 'Triply Fused Zn"-Porphyrin Oligomers: Synthesis, Properties, and Supramolecular Interactions with Single-Walled Carbon Nanotubes (SWNTs)', Chem. Eur. J. 2006, 12, 6062-6070.

D. Bonifazi, A. Kiebele, M. Stöhr, F. Cheng, T. Jung, F. Diederich, H.
F. Diederich, 'Carbon Scaffolding - Building Acetylenic All-Carbon and Carbon-Rich Compounds', Nature 1994, 369, 199-207.

[98] P. Siemsen, R. C. Livingston, F. Diederich, 'Acetylenic Coupling: A Powerful Tool in Molecular Construction', Angew. Chem. Int. Ed. 2000, 39, 26322657.

[99] F. Diederich, M. Kivala, 'All-Carbon Scaffolds by Rational Design', Adv. Mater. 2010, 22, 803-812. Spillmann, 'Supramolecular Nanostructuring of Silver Surfaces via SelfAssembly of [60]Fullerene and Porphyrin Modules', Adv. Funct. Mater. 2007, 17, 1051-1062. 
Entry for the Table of Contents
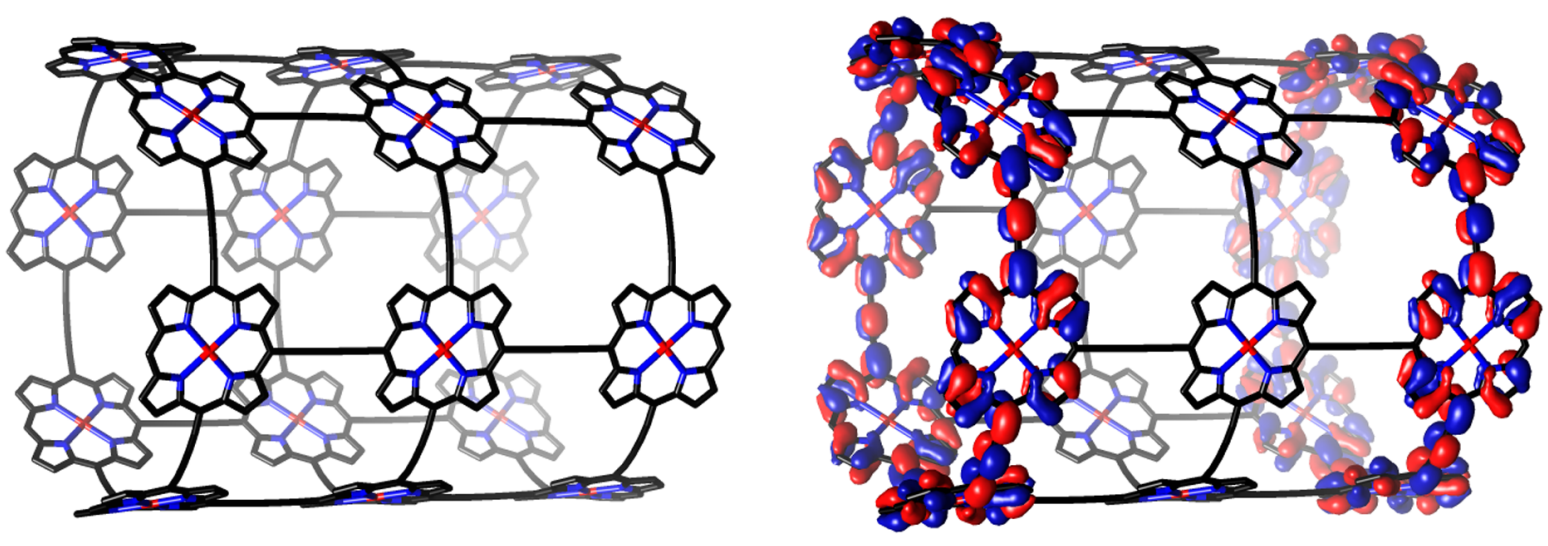